ies Report $\longrightarrow$

\title{
Presenteeism
}

\section{A review of current thinking}

Valerie Garrow

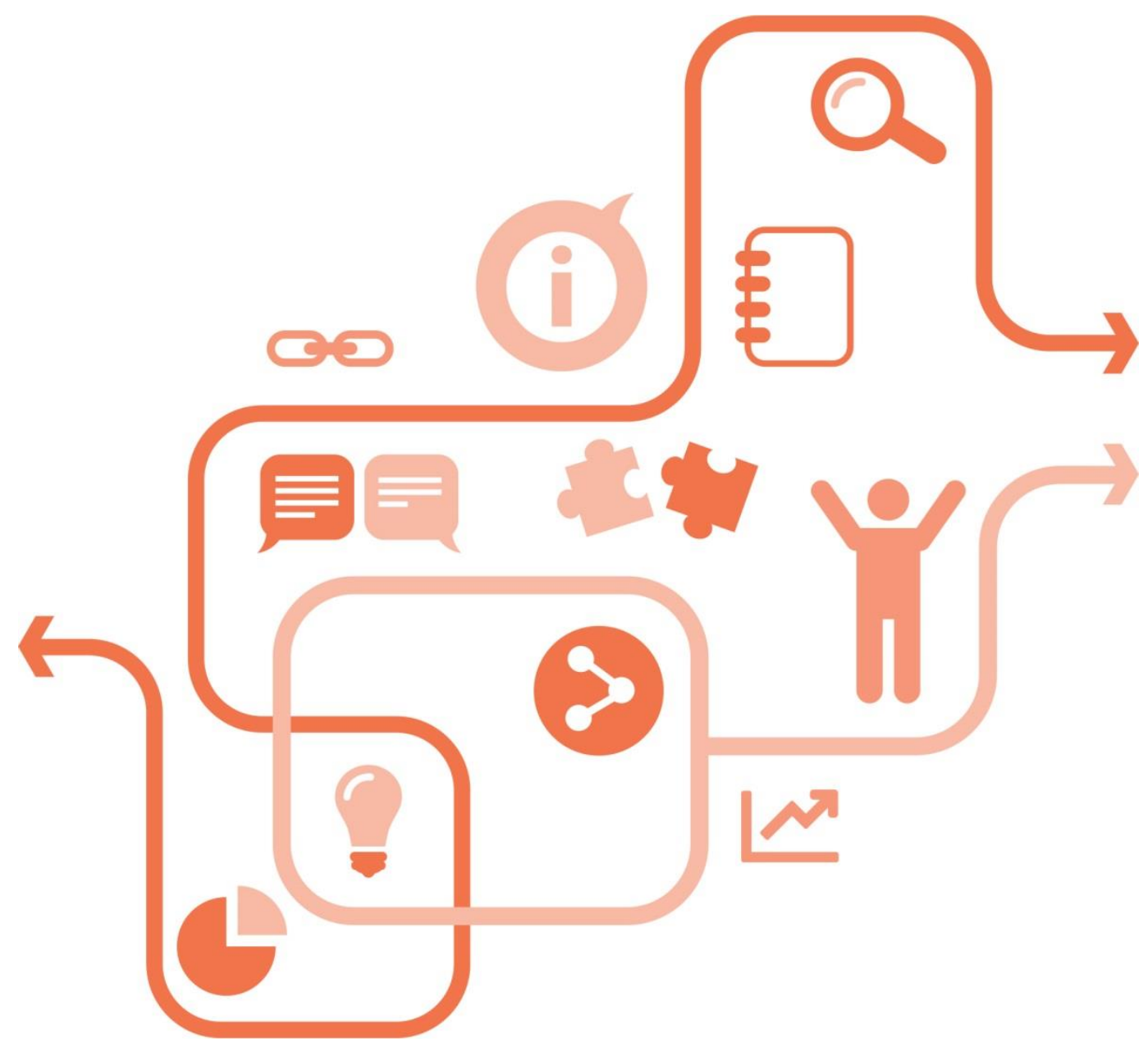

February 2016 


\section{Institute for Employment Studies}

IES is an independent, apolitical, international centre of research and consultancy in HR issues. It works closely with employers in all sectors, government departments, agencies, professional bodies and associations. IES is a focus of knowledge and practical experience in employment and training policy, the operation of labour markets, and HR planning and development. IES is a not-for-profit organisation.

\section{Acknowledgements}

This literature review and recommendations for action, formed part of a study commissioned by EDF Energy France in 2014 and is reproduced with their kind permission. Any queries regarding the work at EDF should be directed to richard.burton@edfenergy.com.

Institute for Employment Studies

City Gate

185 Dyke Road

Brighton BN3 1TL

UK

Telephone: $+44(0) 1273763400$

Email: askies@employment-studies.co.uk

Website: www.employment-studies.co.uk

Copyright @ 2016 Institute for Employment Studies

ISBN: 9781851844548 


\section{Contents}

Executive Summary .......................................................................................................................................... 1

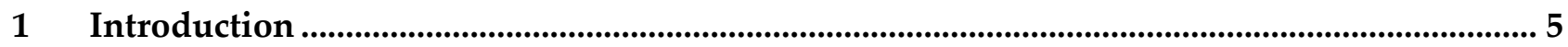

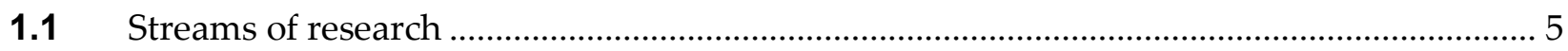

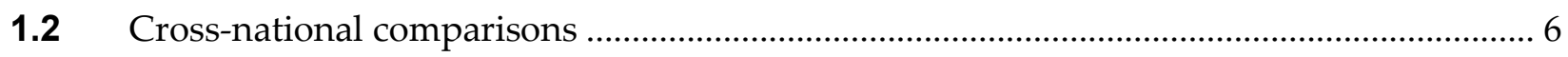

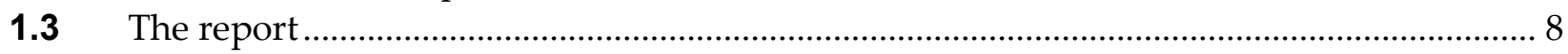

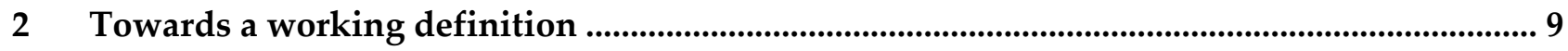

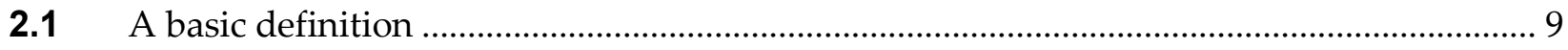

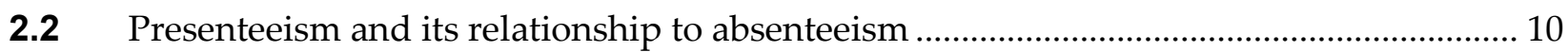

2.3 How can managers/employees assess presenteeism? ........................................................ 12

2.4 Presenteeism as a decision-making process ................................................................. 17

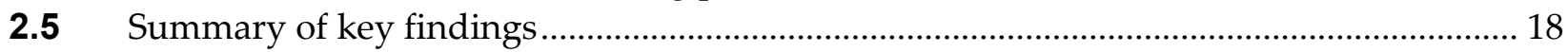

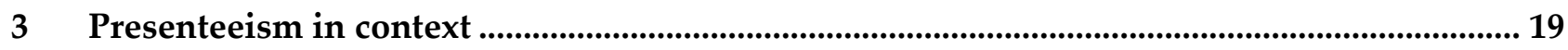

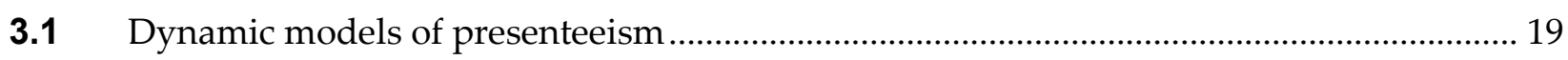

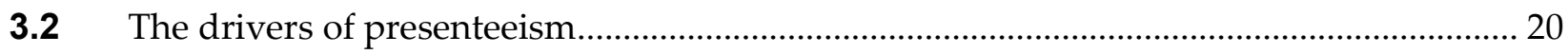

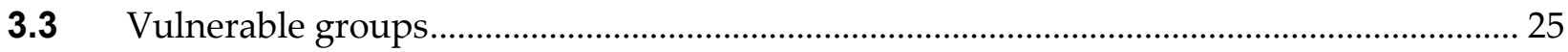

3.4 What can managers take from the dynamic models? ........................................................ 27

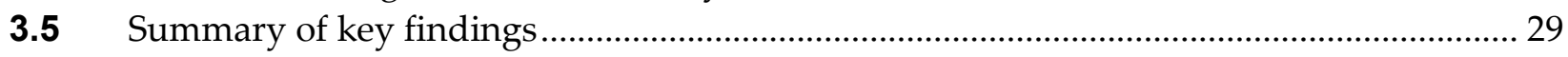

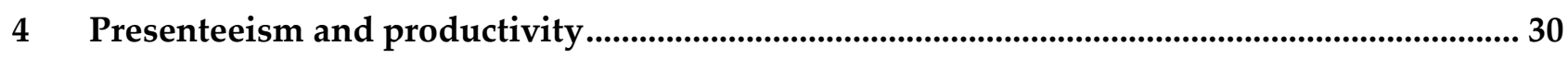

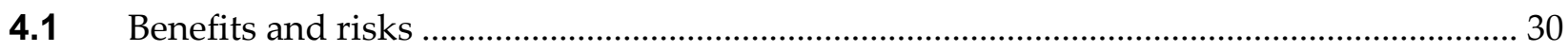

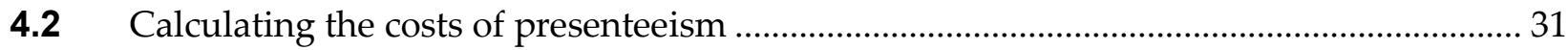

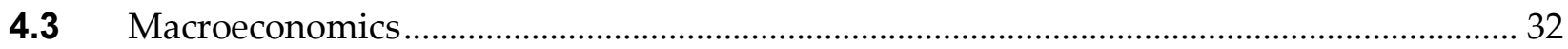

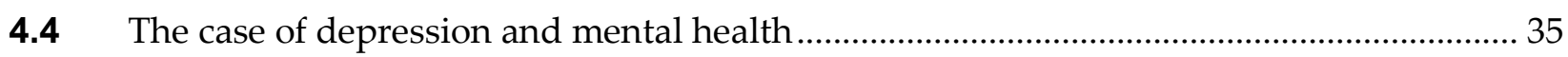

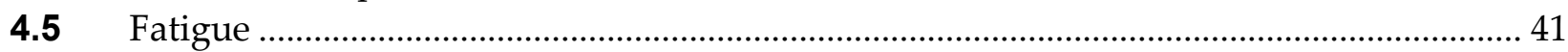

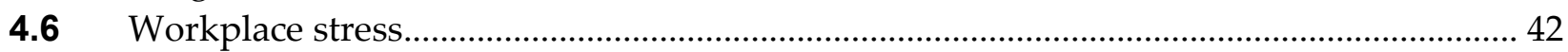

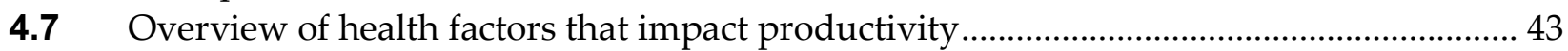

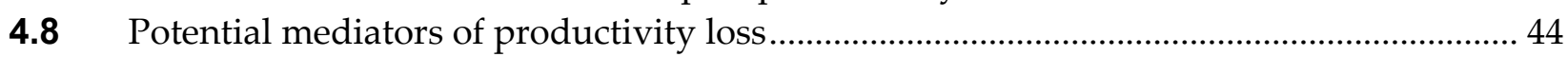

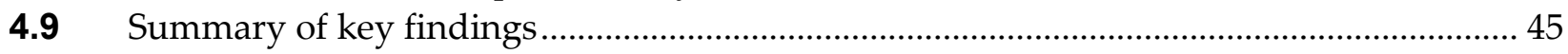

5 Measurement, reporting and benchmarking................................................................................... 46

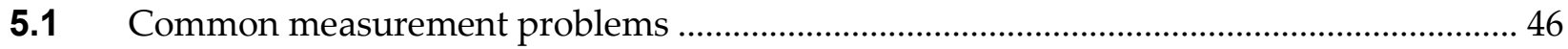

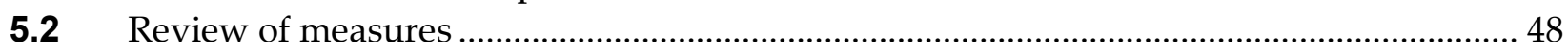

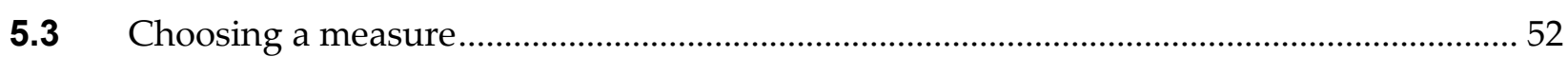

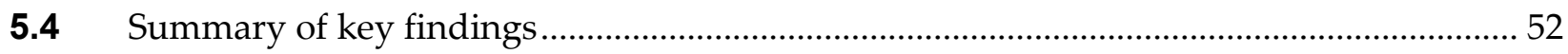

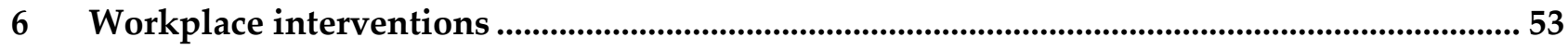

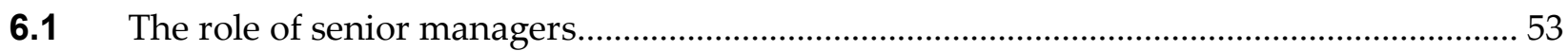

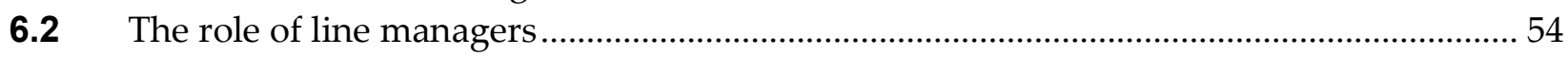

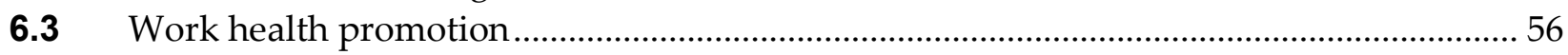

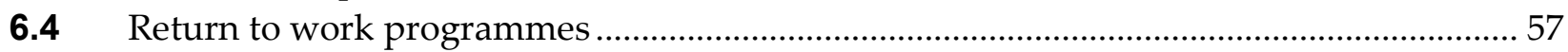

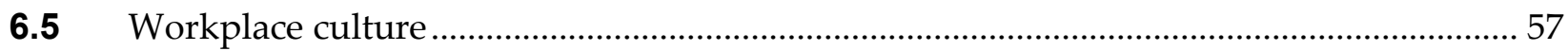

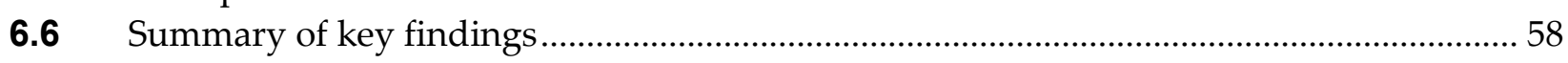

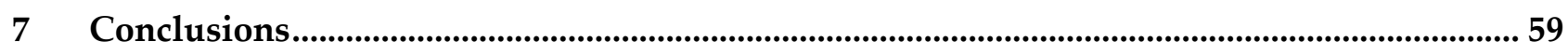

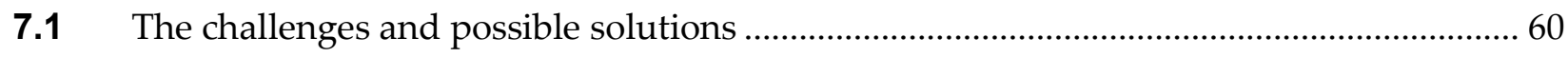




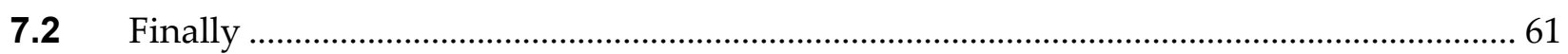

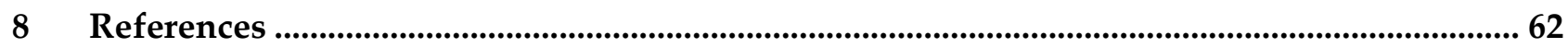

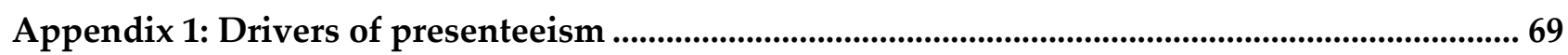

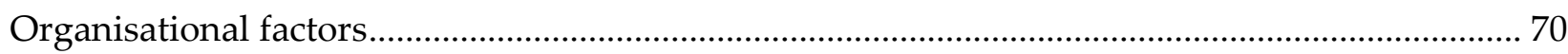

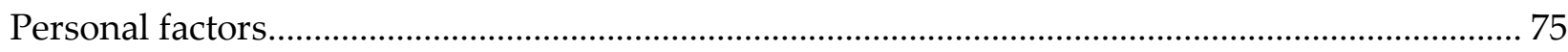

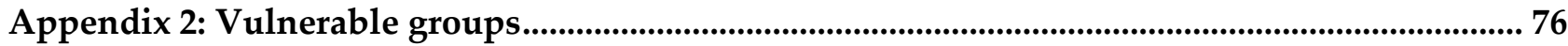

Appendix 3: The impact of presenteeism on productivity ................................................................ 81

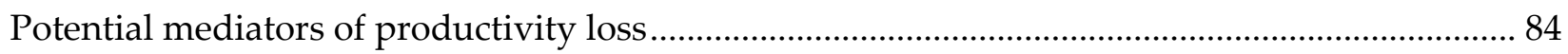





\section{Executive Summary}

As organisations continue to try to achieve more with less, develop leaner systems and greater efficiency, the toll it takes on employees' mental and physical health has climbed the agenda. Increased presenteeism - employees who attend work whilst ill - is one possible outcome of the pressure on organisations to remain competitive and boost productivity. Macroeconomic studies, carried out principally in North America, Canada and Australia, have attempted to put a dollar value on the cost of presenteeism which, on top of healthcare, also includes a drop in productivity at organisational level and the risk of future health problems for the individual. While there are still some methodological and measurement challenges, the evidence suggests that this is an aspect of organisational life that is worth taking seriously.

It seems particularly important to understand the relationship between absenteeism and presenteeism, as organisations drive down the former at the risk of increasing the latter. Organisations may also have concerns that driving down the latter will increase the former. The evidence suggests that presenteeism is both more prevalent than absenteeism, and, unlike sickness absence, is also significantly related to performance. In the long term, presenteeism may also be more damaging for employees' health, morale and productivity. The promotion of a healthy workplace should therefore drive down both absenteeism and presenteeism, rather than one at the cost of the other.

This report is based on an overview of research and current thinking in the field.

\section{Key points covered in the report}

\section{A working definition}

The definition of presenteeism adopted in this report is from Johns (2010), 'showing up for work when one is ill'. This avoids value judgments about when one is too ill to work, does not incorporate consequences such as lower productivity and excludes causes other than ill-health. It also allows for the possibility embraced in this report that both presenteeism and absenteeism can be either positive or negative. For some chronic and psychological illnesses, integration into the workplace can be beneficial, while in other cases it is important to rest and recover. Managers need to work towards eliminating unnecessary absenteeism without increasing negative presenteeism. Policies should be 
seen to make this distinction so that employees understand that they are designed for their own wellbeing as well as organisational health.

\section{Understanding 'illness'}

To help managers, as non-medical experts, understand the different facets of illness in relation to work, we propose a simple framework that takes into account: the frequency and duration of illness (episodic, acute and chronic); the type of illness (psychological or/and physical); and the nature of the work tasks or role. This provides a structure within which managers and employees can assess the impact of a health condition on their work and vice versa, leading to an informed decision on the best course of action for employee wellbeing and team productivity.

\section{Presenteeism as decision-making}

Decisions on whether to 'present' or 'absent' are, however, rarely based on simple health/task information. Other factors (both organisational and personal) come into play. Our framework, therefore, includes the drivers of presenteeism. These range from organisational and team cultures to job-related factors and pressures, and individual differences such as personality, contractual and financial circumstances. The relative dominance of these drivers is heavily context dependent although evidence suggests that work factors tend to be more important.

Research shows that certain groups are vulnerable to presenteeism across the whole organisational spectrum (demographics, personality, seniority, work patterns) but certain groups may be more prevalent in some industries/organisations than others.

A summary of dynamic models is provided, following the decision process from a health episode through to organisational and personal consequences. These models illustrate the multiple drivers that shape the decision but also show the points at which organisations can influence the outcomes by providing healthy workplaces, work adjustments and a supportive management style.

\section{Presenteeism and productivity}

Research shows that people are significantly less productive when unwell. They can also be a hazard to others through passing on infection or making mistakes and potentially aggravating their condition leading to a longer absence. In particular, those with mental disorders report working less carefully, which could lead to dangerous outcomes depending on the type of role. 
Putting a monetary value on presenteeism remains risky and complex but the evidence suggests it is worth taking seriously and macroeconomic studies from the US and Australia suggest that substantial costs are felt throughout the economy.

Depression is worth special attention due to its prevalence, co-morbidity with other illness and lack of visibility. Line managers are often ill-equipped to deal with this form of illness. Fatigue is similarly important because of the mutually reinforcing impact of presenteeism and fatigue in the workplace.

Supervisor support, being able to make work adjustments, health interventions and organisational support for a healthy lifestyle have been shown to mitigate the impact of presenteeism on productivity.

\section{Measuring, reporting and benchmarking presenteeism}

Measurement difficulties relate to both the frequency of presenteeism and its impact on productivity. Studies tend to suffer from common method variance stemming from asking people to self-diagnose their health and then estimate its impact on their own productivity.

Measures are likely to be more reliable as a within company means of monitoring shifts in absenteeism and presenteeism trends (rather than between company comparisons/benchmarking) and in providing data to evaluate the impact of workplace health interventions.

A statistical tool using a zero-inflated negative binomial model (ZIMB) and longitudinal data covering demographic variables, job-related variables and absence data, seems to have captured the phenomenon of presenteeism and this might be a way for organisations to make use of their existing absence data.

Direct measures range from a single item such as that used in the European Working Conditions Survey, 2010 ('Over the past 12 months did you work when you were sick?') to scales with between 6 and 89 items that together tap into presenteeism as a construct. For a full range of measures see Schultz et al (2009). The choice of measures depends on whether a given scale will be a stand-alone survey or be incorporated into another instrument, for example, a staff survey.

\section{Workplace interventions}

Hemp's (2004) article in the Harvard Business Review suggests that workplace interventions to mitigate the impact of presenteeism should be about raising awareness, identifying the issues and education. Research suggests that there are some important areas of focus: 
- The role of senior managers: to ensure employee wellbeing is high on the agenda and fostering a supportive organisational culture and a healthy working environment.

- The role of line managers: several studies highlight the importance of line managers/supervisors as role models, in terms of managing their own absence and presence. Supervisory support is shown to mitigate the negative impact of presenteeism. There is evidence, however, that managers often feel under pressure themselves to control absence but suffer from a lack of required skills and understanding; particularly about mental health issues at work.

- Workplace health programmes are pre-emptive in promoting healthy lifestyles, which in theory should reduce both absenteeism and presenteeism. There tends to be little evaluation on their effectiveness but one US literature review of interventions identified four factors that are related to successful interventions: organisational leadership; health risk screening; individually tailored programmes; and a supportive workplace culture.

- Return to work programmes are important in providing ongoing support to those who have been ill and to focus on their 'capability now' rather than their capability prior to illness. Collaboration with line manager, $\mathrm{OH}$ and $\mathrm{HR}$ is recommended along with more training for line managers.

While presenteeism is a relatively new field of research, early indications suggest that it is worthy of serious attention. It seems to be increasing in Europe and most studies suggest it is linked to productivity loss. The drivers, however, are highly contextual and organisations that want to reduce presenteeism need to understand why it is happening.

Presenteeism has the advantage of relating more strongly to employee wellbeing than absence management. Paying attention to and raising awareness about how to better support employees with ill health, whether through pre-emptive or responsive measures, can also be positioned within the employee value proposition. 


\section{Introduction}

Health and wellbeing at work are key elements in the Europe 2020 strategy for growth, competitiveness and sustainable development. Although since the turn of the century, interest has started to shift from absenteeism to presenteeism, and from sick notes to fit notes, organisations continue with the traditional focus on absenteeism. Today, with an accumulating body of evidence suggesting presenteeism might pose greater risks than absenteeism, few organisations quantify productivity loss related to people who are at work but underperforming due to illness.

Furthermore, with the introduction of absence control policies such as 'return to work' interviews, home visits, absence scores and trigger points, there is concern that such interventions might exacerbate the problem and lead to an increase in presenteeism and longer term health problems for individuals.

This report is based on an overview of research and current thinking in the field.

\subsection{Streams of research}

There are two key streams of interest in the literature to date (Johns, 2010):

- British and Europeans have mainly focused on the frequency of presenteeism as a reflection of job insecurity and other occupational characteristics.

- Americans have been concerned with the productivity consequences of presenteeism as a function of various illnesses, while ignoring the causes of working while ill.

This is perhaps not surprising in view of the American healthcare system and the reliance on corporate and insurance schemes. Wellness programmes have become an important response to cutting the cost of healthcare and they clearly have a vested interest in this field of research. In the UK too, since the Black Review (2008) there has been an emphasis on promoting 'wellness' cultures with good line manager support and a shift away from thinking that work is damaging unless fully fit. The Statement of Fitness for Work (known as a 'fit note'), was introduced in April 2010 across England, Wales and Scotland to improve back-to-work advice for individuals on sickness absence and communication between individuals, doctors and employers on what a patient could do at work, thereby reducing sickness absence levels. 
The literature and research is approached from different disciplines:

- Occupational health and medical research focus on the mutual impact of work and medical conditions.

- Management and organisational behaviour have been interested in culture and support as well as recognising the potential business impact of various conditions on productivity. The organisational role is becoming more widely recognised and the Towers Watson 2013 global Staying@Work Survey suggests that establishing a culture of health is the top priority for organisations. They found that employers are recognising that health is a total business issue that affects workforce performance.

\subsection{Cross-national comparisons}

Research into presenteeism has a clear geographical bias (principally US, Canada, Australia and Scandinavia) and much of it has been carried out in the health sector. Cross-national comparisons have to date been relatively unsatisfactory due to measurement and definitional issues which are highlighted in Section 5.1.

Monneuse (2013) says that in France research is almost non-existent and in his blog spot claims that managers are simply not interested. There have, however, been a couple of statistical studies using absence data sets in a French bank (Bierla et al, 2011) and a French hospital (Huver et al, 2012).

The main comparative data across Europe comes from a single item included in the 2010 European Working Conditions Survey (EWCS) of 40,000 respondents in 34 countries. The item used was, 'Over the past 12 months did you work when you were sick?' and 'If yes, how many working days?' Positive responses were obtained from 40 per cent of all respondents.

Considering both genders together, the prevalence of presenteeism ranked highest in Montenegro, followed by Slovenia, Malta, Denmark and Sweden (all well above 50 per cent), and lowest in Italy, Portugal, Poland and Bulgaria (23-25 per cent). Average days of presenteeism (Figure 1.1) were 3.1 in the whole sample, with a slightly higher figure for women (3.4 days) than men ( 2.9 days). France's average was around four days, slightly higher for women than men, while the UK has an average of three days and virtually no gender difference. 


\section{Figure 1.1: Average days of presenteeism, by country and gender, across Europe}

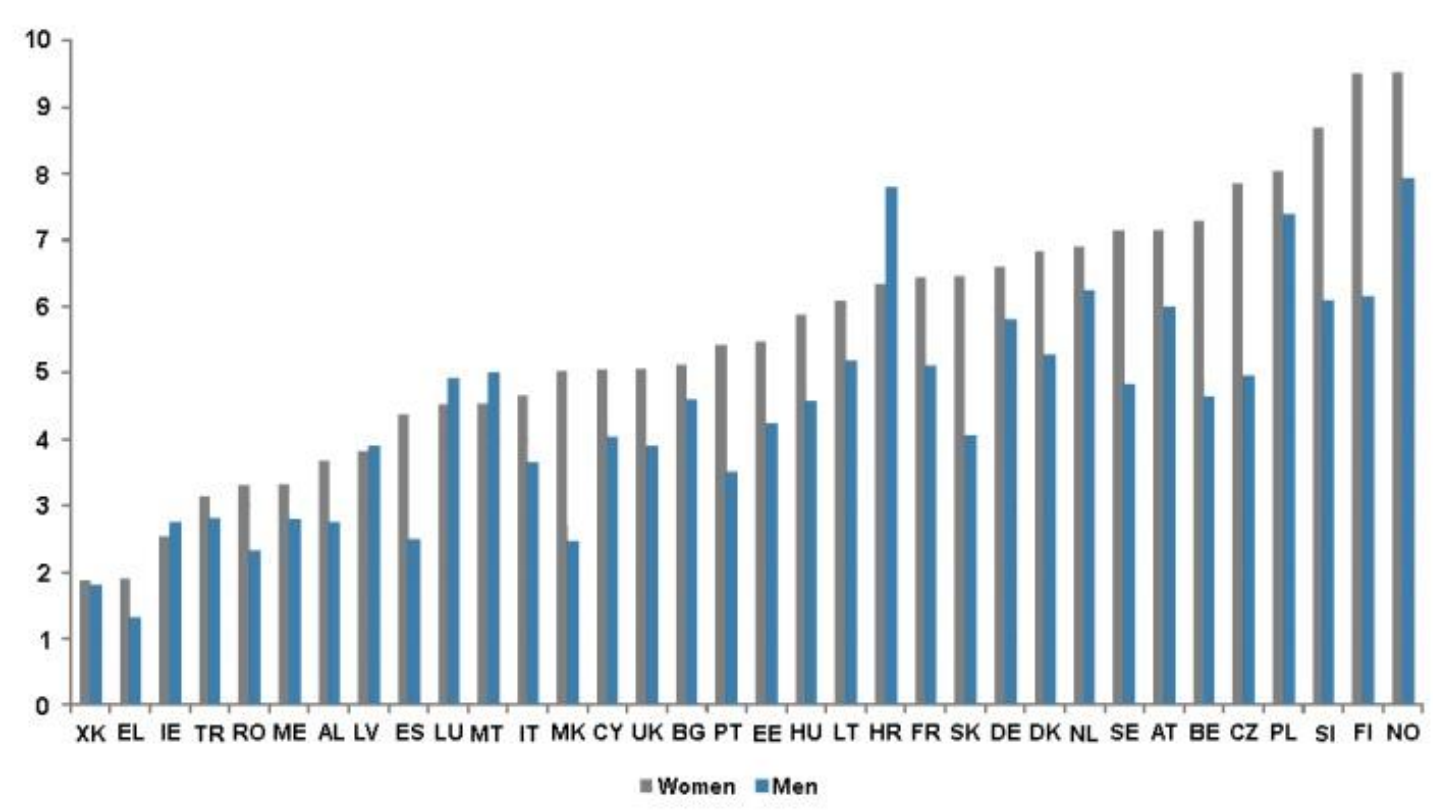

Source: Eurofound, 2012

A further point of interest is that many countries with high presenteeism also have high absenteeism such as Slovenia (SI $-3^{\text {rd }}$ highest on absence with a similar number of absence days), Finland (FI $-2^{\text {nd }}$ highest on absence with nearly eight absence days) and Norway. This is not always the case, however, and Montenegro (ME) has low absence. According to Eurofound, most aggregate figures say that the prevalence of sickness absence in Europe is 40 per cent, with an average number of five days of absence per year.

Eurofound use the EWCS raw data but with a higher number of days as a threshold in order to have a more clear-cut representation of the phenomena:

- Sickness absence, based on five or more days of sickness absence in the previous year (as suggested by Eurostat in the methodology for the European Statistics on Accidents at Work (ESAW)) was reported by 22.5 per cent of men and 28.1 per cent of women.

- Sickness presenteeism, based on at least two days of presence while ill during the previous 12 months, (as in most previous research on sickness presenteeism) was reported by 36.3 per cent of men and 40.4 per cent of women.

Eurofound note that the prevalence (percentage that say they have been to work sick) of sickness presenteeism observed in the EWCS sample is lower than that reported by other researchers using the same definition of presenteeism (two or more days of presence in the previous year), who tend to report sickness presenteeism of around 50 per cent or above. 
Monneuse (2013) points out the wide range of results across European data, indicating the current difficulties of cross-national comparison and the need to use average percentage rates with caution.

\subsection{The report}

Presenteeism measurement is a challenge at the organisational level as well as the national level as it is not always apparent that people are unwell or the extent of their impairment. People might disguise symptoms with medication, which in itself can pose a hazard, for example to those operating machinery or driving. Context makes definition particularly difficult.

This report seeks to answer several questions:

Section 2: How can presenteeism be usefully defined while taking into account some of the complexity of illness and the variety of work tasks, and what is its relationship to absenteeism?

Section 3: What drives presenteeism in an organisation, how can vulnerable groups be identified and how should managers use this information?

Section 4: What is the impact on productivity and how can that be mitigated?

Section 5: How can presenteeism be measured and reported?

Section 6: What actions could be put in place to ensure that presenteeism does not become a problem when absenteeism falls?

Section 7: The value, challenges and options for further research. 


\section{Towards a working definition}

The term 'presenteeism' has evolved over time. Over 30 years ago there were already concerns about using absence figures as a measure of productivity when Steers and Rhodes (1978) suggested that some absenteeism can be good for an organisation in order to avoid unfavourable consequences for both organisations and employees. For a time, presenteeism was used quite broadly as the opposite of being absent but further research reveals the picture is more complex.

In order to capture some of this complexity, this section starts with a basic definition, considers the relationship between absenteeism and presenteeism, proposes a simple model to help managers start to contextualise illness in the workplace and then moves on to explore the need for more dynamic models relating to decision-making, which are covered in Section 3.

\subsection{A basic definition}

Currently there are some nuances in the various uses of the term worth noting:

- An element of value judgement: Aronsson and Gustafsson (2005) propose that sickness presenteeism 'designates the phenomenon of people, despite complaints and ill health that should prompt rest and absence from work, still turning up at their jobs'. This implies that presenteeism is always negative and disregards the beneficial impact of being at work for self-esteem and comradeship with sufficient support from the organisation.

- Reduced productivity: Some definitions now include the loss of productivity so that presentees are people who are present but not working to full capacity because of their impairment. This, however, builds into the definition a complex outcome element that is both difficult to define and to measure.

- Reasons other than sickness: Presenteeism has also been used to describe people who are present but unproductive for a range of reasons such as disengagement, distractions due to worries outside work or simply trying to impress others by putting in 'face time'. Monneuse (2013) uses the word 'surprésentéisme' (also implying a value judgement) to distinguish it from other forms of 'présentéisme', which go beyond the 
boundaries of health. Similarly other researchers often use the term 'sickness presenteeism'.

After reviewing multiple definitions, Gary Johns (2010) warns of 'definition creep' beyond health and advises against ascribing motives or incorporating consequences. This report adopts his definition:

'The most recent scholarly conception of presenteeism involves showing up for work when one is ill.'

This opens the way to consider the positive (desirable) and negative (undesirable) aspects of both presenteeism and absenteeism.

\subsection{Presenteeism and its relationship to absenteeism}

Chatterji and Tilley (2002) found through mathematical modelling that policies implemented to reduce absence, such as a reduction in sick pay, were more likely to increase presenteeism, which in turn could lead to more illness and lower productivity. Taylor et al (2003) concurred, suggesting that policies encouraging attendance at the cost of the employee, adversely impact on employee morale and increase absence.

Originally thought of as the opposite of absenteeism, the relationship between presenteeism and absenteeism proves more complex. Organisations are understandably keen to reduce unnecessary absence (negative absenteeism); which might result from a sense of entitlement to a certain number of sick days, duvet days, cultures of absence, etc. Policies designed to tackle this sort of system abuse, however, inevitably put pressure on those who are genuinely sick and needing rest (positive absence) to be at work (negative presenteeism). Depending on the nature of their condition, others would prefer to be at work and benefit from it with the right kind of support (positive presenteeism).

Ideally absence policies should recognise and discriminate between positive and negative absenteeism and presenteeism to achieve optimum outcomes. Consider Figure 2.1 below: 
Figure 2.1: The impact of a successful absence policy

\begin{tabular}{|l|c|l|l|}
\hline & Presenteeism & \multicolumn{2}{|c|}{ Absenteeism } \\
\hline Positive & \multicolumn{2}{|c|}{ Encourage } & \multicolumn{2}{|c|}{ Encourage } \\
\hline Negative & Reduce & Reduce & Eliminate \\
\hline
\end{tabular}

The four white boxes represent positive and negative presenteeism and absenteeism. The aim of a successful policy is to see people move out of the negative spaces into the two positive spaces:

- From negative absence:

- Eliminate unwarranted absence (eg when people are not sick but might feel entitled to a day off because they haven't used any sick leave, feel like a duvet day, etc) without impact on presenteeism. These people simply leave the equation.

- Reduce unnecessary or prolonged absenteeism (where people have a health condition but could usefully do different duties and would like to be back at work). By offering good return to work provision and supervisor support move this group into the positive presenteeism space.

From negative presenteeism:

- Encourage people who are too ill to work to make use of genuine absence provision and stay at home. They move into the positive absence space, aiding their own recovery and avoiding the spread of infection at work.

- Encourage those, who with help and adjustment to their work practices/schedules can remain productive rather than having to take absence. Again with the right support they should move from negative presenteeism, where tasks are detrimental to health and vice versa, to positive presenteeism where workload is adjusted to meet capability.

While the quadrants help us to distinguish types of absence and presenteeism, it doesn't mean that these are necessarily populated by different people. Monneuse (2013) argues that rather than being opposites, absentees and presentees are often the same people who suffer from poor health. Absenteeism and presenteeism are simply the responses people choose to make day by day in the course of managing their condition. Hansen and Andersen's (2008) large scale study of nearly 13,000 Danish workers suggests that the strong association between sickness absence and sickness presence indicates that the two 
phenomena are indeed outcomes of the same 'decision process' and that taking sick leave on one occasion will make a person more reluctant to do so subsequently, thereby leading to sickness presence.

This relationship between presenteeism and absenteeism indicates that organisations should develop health strategies that take a more holistic view of employee health rather than focus simply on reducing absence figures. Vézina et al (2011), who conducted the Quebec Survey on working conditions and health, suggest that organisations should 'go beyond simply controlling sick days in medico-administrative terms and must act as well on the organisational and physical work demands associated with increased presenteeism'. This is particularly relevant in the light of the Work Foundation's findings (Ashby and Mahdon, 2010) that, unlike sickness absence, sickness presence is significantly related to performance. They conclude that improving wellbeing should reduce both absenteeism and presenteeism.

\subsection{How can managers/employees assess presenteeism?}

While Johns' simple, non-judgemental definition above is useful in isolating the construct from its antecedents (causes) and consequences (outcomes), the concept of 'illness' is likely to prove most challenging to managers who have no medical expertise.

The evaluation of capability and being 'too sick to work' is not straightforward with judgement being made subjectively. Research suggests that people often disregard doctor's advice and make their own judgments (Monneuse, 2009). A framework is therefore helpful in the workplace for managers and their staff to consider when people who are sick should be at work.

Figure 2.2 outlines the factors that managers and staff need to take into account when deciding whether it is appropriate for someone with a health condition to be at work. At the base two triangles deal with the illness itself and its manifestations. The top triangle considers the demands of the job. The middle triangle reminds us that that there are many other drivers that encourage people to 'present' rather than 'absent'. These are considered in the next chapter. 


\section{Figure 2.2 When is it appropriate to be at work when sick?}

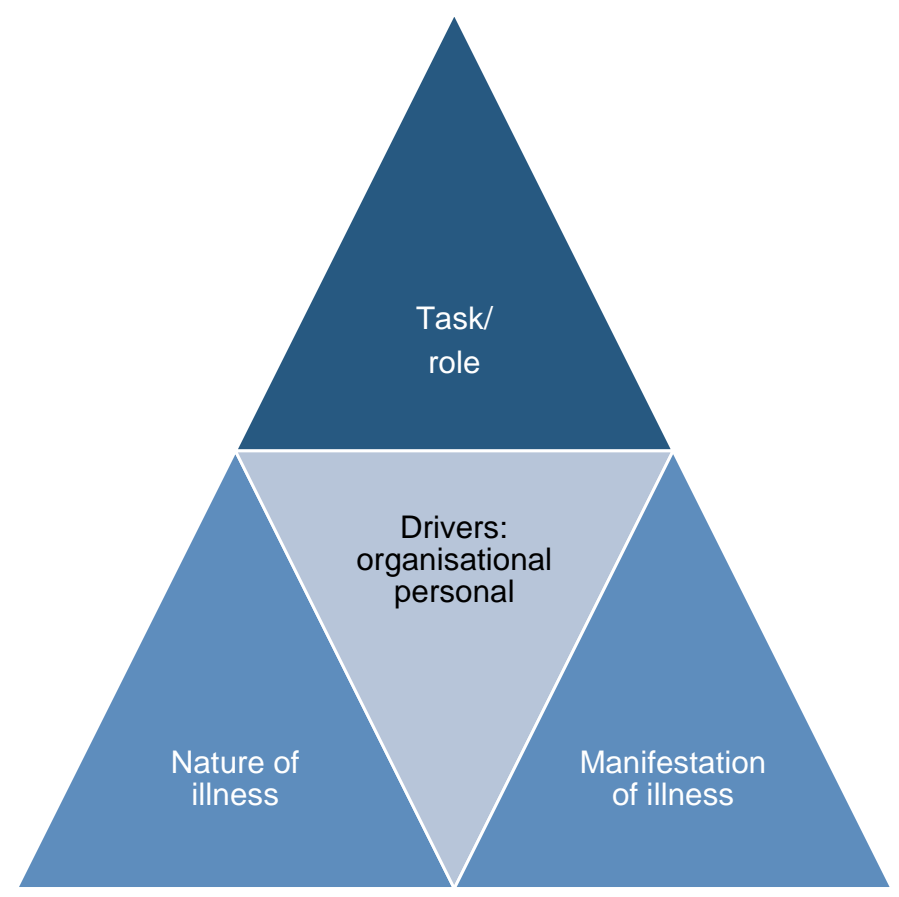

Initially managers and employees need to understand how the manifestation of the condition (severity and duration) as well as its nature (psychological or physical) is likely to impact on or be affected by the work tasks or role. These dimensions are explored in more detail.

\subsubsection{The manifestation: severity, duration and frequency}

Important dimensions of illness are its frequency and its likely duration. Gosselin and Lauzier (2010) provided two options of occasional and chronic manifestations, while Johns (2010) distinguishes between episodic, acute and chronic conditions. This fairly simple categorisation is helpful for line managers in deciding what support they will need from $\mathrm{OH}$ or $\mathrm{HR}$ and what resources are available.

Episodic: refers to illnesses such as migraine, allergies or conditions that come and go periodically. With this type of complaint those afflicted have some point of reference and prior experience of when the illness becomes too severe to work. Line managers should discuss with employees how their condition can best be managed, the implications of taking medication at work (for example the risks of operating machinery or driving, impaired judgement from drowsiness) and possible adjustments to the work schedule and tasks to accommodate any impairment (such as working from home to avoid driving, working away from computer screens with migraine, back office work in a call centre etc).

Acute: includes illnesses that may be infectious, isolated but prone to worsen without due care. The danger of epidemics such as SARS and other serious flu viruses has led to 
concerns about the spread of disease at work, which is particularly relevant for health workers. In some acute cases such as the avian flu epidemic, there will be emergency guidelines designed to minimise risk of spreading infection as well as possible preemptive programmes of vaccination. Whether people should be at work with heavy colds, however, is a grey area requiring a judgement and may depend on the type of work and exposure to other vulnerable people (eg health workers, manual and outdoor roles in harsh weather conditions, risk of spread to colleagues in confined conditions) or individual factors (general health, risk of worsening condition). It may be useful to provide guidance to managers through a policy defining how to make the judgement of the circumstances in which a team member can work despite a health condition.

Chronic: refers to ongoing long-term conditions such as arthritis, heart disease, diabetes, HIV and cancer. An OECD study (2010) concludes that due to limited capacity few in this category manage to stay at work. However, according to ENWHP (2013) the exorbitant cost of early retirement, the maintenance of chronically ill patients, the shortage of skills and demographic change in Europe means that it is vital to retain these employees. They recommend guidelines both for prevention/mitigation and reintegrating/keeping people involved in work. The concept of 'positive' presenteeism is also important here for individuals' quality of life and self-realisation. This may, of course, mean that people are less productive and focusing on what they are able to do (their capacity now) rather than their incapacity. A return to work, for example, might cover several stages over a period of time, during which they can make a valuable contribution, albeit at a level below their personal optimum.

\subsubsection{The physical and psychological nature of illness}

The second of Gosselin and Lauzier's dimensions highlights the distinction between the physical and psychological nature of illness and the impact each has on performance; often functional limitations for the former as opposed to concentration or judgement problems with the latter.

The employment rate of people with a mental disorder ${ }^{1}$ is around $55-70$ per cent, or 10-15 percentage points lower than for people without a mental disorder, on average across the OECD. According to the OECD (2012) workers with a mental disorder are absent from work for health reasons more often than other workers (32 per cent versus 19 per cent), and when they are absent, they are away for longer ( 6 versus 4.8 days of absence). An

\footnotetext{
${ }^{1}$ According to the OECD this refers to reaching a threshold of diagnosis according to two psychiatric classification systems: the International Statistical Classification of Diseases and Related Health Problems (ICD-10) and the Diagnostic and Statistical Manual of Mental Disorders (DSM-IV). The most relevant disorders are mood, anxiety, substance abuse, somatoform and psychotic.
} 
issue of concern is that across OECD countries almost half of those with a severe mental disorder and over 70 per cent of those with a moderate mental disorder do not receive any treatment for their illness.

The distinction between mental and physical illness is also important because employees believe that it is perceived very differently in the workplace, which could lead to different reporting behaviours. A recent UK survey by mental health charity MIND (October 2013) shows that less than a third (32 per cent) think that time off for stress is treated as seriously as time off for a physical illness and nearly half (42 per cent) believe that time off for stress is seen as an 'excuse' for something else.

Psychological illness presents a problem for line managers as those afflicted often suffer in silence. The MIND survey of 2,000 workers shows:

- Forty-five per cent of workers feel that staff are expected to cope without mentioning stress at work.

- Thirty-one per cent said they would not be able to talk openly to their line manager if they felt stressed.

- Twenty-two per cent of workers felt their boss takes active steps to help them manage stress.

MIND concludes that 'it is vital that managers are equipped with the tools they need to be able to confidently and effectively support their staff, whether they are experiencing stress or other mental health problems as a result of work or other factors'.

Mental illness and its impact on productivity are revisited in Section 4.4.

\subsubsection{The nature of the task/role}

In some cases, such as highly infectious acute conditions, it might never be appropriate to be in the workplace. Even in these cases, however, individuals might feel well enough to work from home or to cover urgent calls if they are not required to rest. For other types of illness, judgements can often only be made in relation to the type of tasks eg a pianist with a broken finger, a sports person with a sprained ankle, an intensive care nurse with a heavy cold, etc. In some cases people can be assigned to different duties (desk duties, simple but necessary admin tasks, working from home).

Managers should consider and discuss with the employee the mutual impact of work and illness and what circumstances might warrant a leave of absence or an adjustment in work tasks. This could form the basis of a simple check list. An illustration of suggested items is given below as an example: 


\section{Dimension 1 - The manifestation: severity, duration and frequency}

Some questions designed to ascertain whether the illness is episodic, acute or chronic:

- Is the employee suffering from a recurring but temporary illness?

- Are they taking medication which might affect their work or pose a danger to themselves and others eg drowsiness, poor decision making?

- Is the employee able to manage the symptoms and make the appropriate decision about fitness to work?

- Is complete rest the best course of action to avoid a worsening condition?

- Is the employee an immediate danger to others - patients, customers, colleagues? eg showing symptoms of an infectious disease. Are there company guidelines in this event?

- Does the employee have a long-term condition? If so are there regular discussions with $\mathrm{OH}$ on how this can best be managed? What task or rostering adjustments could usefully be made to help the individual?

\section{Dimension 2 - Type of illness (physical or mental)}

- Is the illness physical and what are the symptoms that might be aggravated by the work role or might in turn impact the performance of those tasks eg pain, physical disability, a condition that might be aggravated by certain activity?

- Is the illness psychological and what is known of the history or manifestations of the condition? Is the employee open to discuss the condition? Does it have an impact on relationships in the workplace?

- Is the individual suffering from a combination of physical and mental conditions that are mutually detrimental?

- Is the individual taking appropriate medication and what are the implications for the role/task?

- What support does the employee require in performing their role? How will OH, HR and managers work together to ensure appropriate support/work adjustment?

- How much latitude does the employee have to adjust the role for themselves when required? 


\section{Dimension 3 - The employee's task/role}

- What aspects of the task might be directly affected by the illness as presented? Are they physical or mental restrictions?

- How might workloads be distributed within the team and the team generally provide support to the individual?

- What aspects of the role might aggravate the employee's condition eg lifting, heavy workload, tight deadlines?

- Can work/task adjustments be made to help with the temporary impairment?

- Is there flexibility to work from home? How might that impact the condition if the person needs to rest?

The model above provides a simple framework for discussion and for risk management regarding the appropriateness of being at work when ill. While this provides a good starting point, decisions about when to report for work in spite of illness are rarely based on the simple assessment of the illness compared to the task.

\subsection{Presenteeism as a decision-making process}

Baker-McClearn et al (2010) describe presenteeism as a complex 'problem' that is continually being shaped by individual and organisational factors such as peak periods and deadlines, pressure from colleagues and managers and individuals' own motivation and assessments of the impact of their absence on clients and colleagues.

The next section introduces the complexities of what drives presenteeism and considers more dynamic models of the decision-making process. 


\subsection{Summary of key findings}

The most helpful and concise definition of presenteeism is 'showing up for work when one is ill'. This avoids the more complex problems of defining motives/precursors and/or consequences, ie trying to incorporate cause and effect in one definition. It also avoids conveying a value judgement.

Presenteeism (and absenteeism) can be positive or negative. For some chronic and psychological illnesses integration into the workplace can be beneficial for individuals, while absence is beneficial in other cases. Managers need to be able to work towards eliminating unnecessary absenteeism without increasing negative presenteeism. Policies should be seen to make this distinction so that employees understand that they are designed for their own wellbeing as well as organisational health.

Our framework suggests that managers need to consider when presenteeism is appropriate and what measures might be taken to assist presentees in the workplace and we offer a potential check list, which should include some items relating to risk management. 


\section{Presenteeism in context}

Monneuse (2013) identifies a common thread in employees across the whole organisational spectrum who engage in 'surprésentéisme' which is that they are 'sous pression'; under pressure to be at work. This pressure (or perceived pressure) might come from colleagues, clients, managers or other players or even from themselves and might, in itself, be a danger to health and productivity. He therefore the poses the question as to whether presenteeism is a choice or a constraint.

The 'causes' of presenteeism can be divided into those that are voluntary (such as interest or professionalism) and those that are involuntary (where the cost of absence is too high for the employee or the organisation, for example, where people are hard to replace or there is job insecurity). Brun and Biron (2006) suggest that involuntary causes are the most frequent, representing 54.4 per cent of presenteeism cases.

\subsection{Dynamic models of presenteeism}

While decisions are rarely made on purely factual grounds, a study in Sweden showed that the majority of employees take the decision to call in sick quite seriously, even when they are experiencing severe neck or back pain (Hansson et al, 2005).

The researchers Johns (2010) and Aronsson and Gustafsson (2005) each offer dynamic models as the basis of a research agenda. These follow the decision process showing precursors and consequences. Both highlight the importance of personal and organisational context.

A range of work-related and personal factors form part of the decision-making process; from the organisational culture to practical considerations such as sick pay on the one hand and individual personality to perceptions of legitimacy on the other. The decision to absent or present then has consequences which in turn may have further repercussions such as more ill health or implications for productivity. 


\section{Figure 3.1: A Dynamic Model of Presenteeism and Absenteeism}

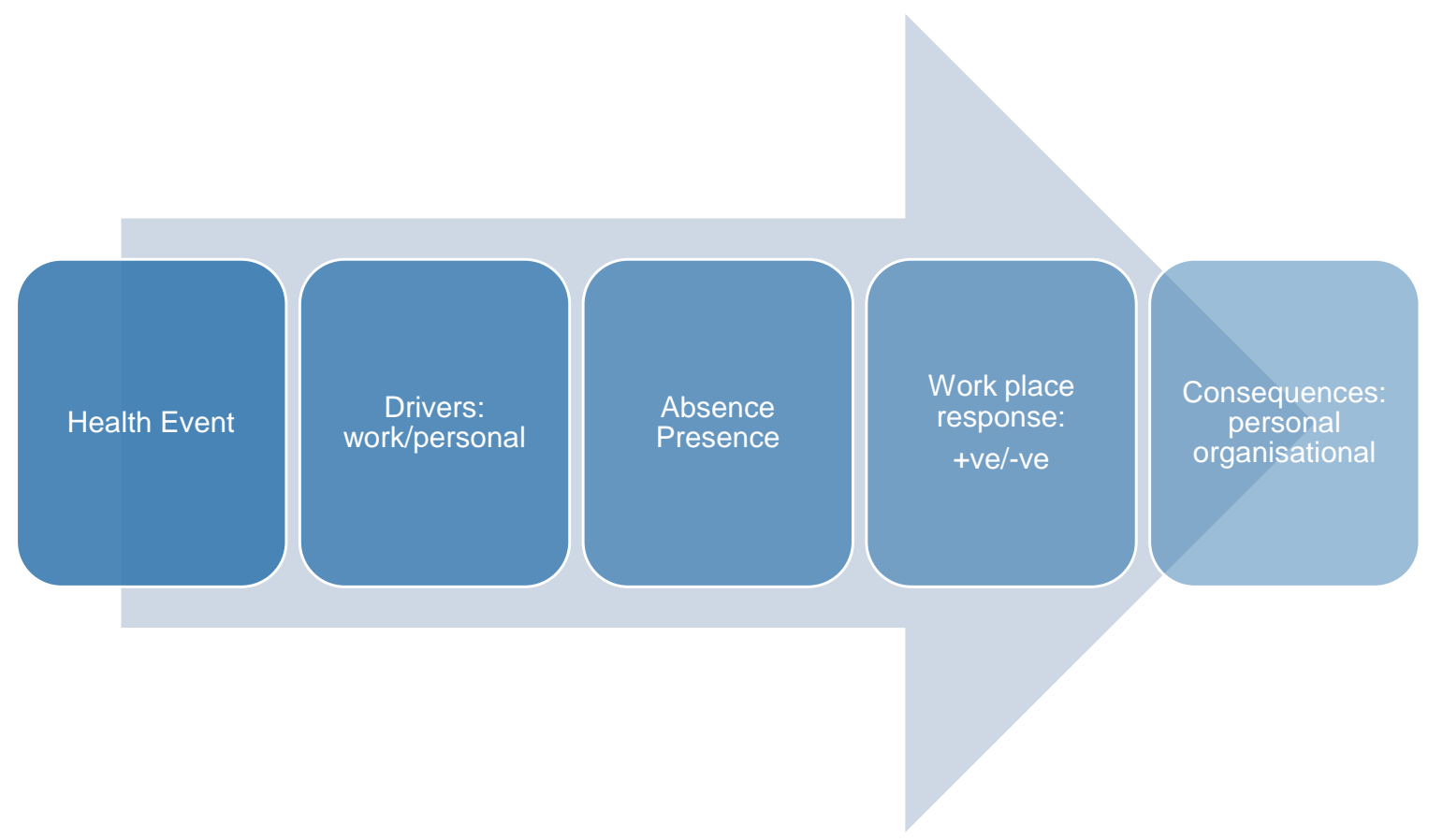

Aronsson and Gustafsson (2005) focus on the long-term outcomes (both benefits and downsides) and the importance of the organisational response. In doing so they demonstrate the concept of positive and negative presenteeism and absenteeism, as the impact on health is mediated by either 'destructive' (relating to an unsupportive environment) factors or 'salutogenic' (beneficial/promoting wellbeing) factors in the workplace. Baker-McClearn et al (2010) also suggests that performance and wellbeing are more closely related to the organisational reaction to presenteeism and absenteeism, ie how the organisation accommodates illness in the workplace, rather than the act itself.

Absenteeism can similarly lead to positive (return to work) and negative outcomes (exclusion from the workplace) which impact wellbeing.

These dynamic models demonstrate the complexity of decision making in an organisational context and identify personal and organisational factors that impact decision making. Clearly it is important to understand more about the initial reasons behind employees' decisions to work while ill. In other words what drives presenteeism?

\subsection{The drivers of presenteeism}

There are many different studies, both qualitative and quantitative, that identify factors that 'drive' presenteeism. Some start from a hypothesis that certain factors will be important. Other studies using large scale datasets are able to identify correlations with 
many other variables. The relevant studies are shown in a set of tables in Appendix 1. These are summarised below: the first three cover organisational factors (culture, policy, job design) while the fourth deals with the individual factors that influence decisions on whether to 'present'. According to Hansen and Andersen (2008), work-related factors have a slightly greater effect.

\subsubsection{Organisational factors}

\section{Cultural factors (professional, team, organisational)}

Some of the organisational factors can be said to reflect the culture, which might be at the organisational level, the team level or the professional level.

At the professional level:

- The needs of others: Presenteeism is prevalent in jobs where attendance has a great influence on other people and on their primary needs such as the education sector, and care and welfare (Aronsson et al, 2000) but that was not the case where hospital service workers were not directly caring for patients (Huver et al, 2012).

At the team level:

- Concerns for colleagues: Employees want to spare their colleagues additional workload when there is no replacement and will therefore come to work when ill (Caverley et al, 2007).

- Manager and supervisor behaviour: Several studies show the importance of managers and supervisors as role-models (Huver et al, 2012; Caverley et al, 2007). Often they feel a sense of responsibility for the team but the evidence points to their employees feeling they therefore have to do the same. In other words, high manager presenteeism = high employee presenteeism. (Bierla et al, 2011; Ramsey, 2006). Negative supervisor behaviours, meanwhile, are associated with employee job-stressrelated presenteeism (defined as a form of psychological strain whose antecedent is job stress) (Gilbreath and Karimi, 2012 - for more on this study see Section 4.6).

At the organisational level:

- The influence of work culture: Dew et al (2005) describe three very different work cultures which nevertheless all foster presenteeism. Firstly a public hospital ('battleground' culture with distant management but where professional and ethnic identity and institutional loyalty foster presenteeism); secondly a private hospital ('sanctuary' culture where strong teamwork and good relationships with co-workers foster presenteeism); and a manufacturing firm ('ghetto' culture where poor working conditions and insecurity prompt presenteeism). 
- Work ethic: Case study data (Baker-McClearn et al, 2010) identified a perception that taking time off sick was a sign of under-performance, particularly in private sector organisations. This work ethic seemed to be passed down as perceived wisdom from older and longer serving employees.

- Organisational commitment: In one large study (Hansen and Andersen, 2008) perfect attendance was seen as a sign of loyalty and organisational commitment.

\section{Organisational policies and economic climate}

While organisational policies also reflect culture they are shown separately in Appendix 1 as they are likely to inform a different kind of decision-making relating to self-interest. This might reflect a concern for job security, financial benefits or penalties and general financial insecurity. These include:

- Fixed term contracts: Several studies identify higher presenteeism for those who are hoping to achieve permanent status (Caverley et al, 2007, Huver et al, 2012), particularly where there is competition between several employees on fixed term contracts (Bierla et al, 2011). In one Finnish hospital study, absence nearly doubled when employees moved from fixed term to permanent contracts (Virtanen et al, 2003). Johns (2010), however, notes another Scandinavian study that shows permanent employees are more likely to report presenteeism, so findings are not always consistent on this factor and may be more dependent on organisational culture.

Job insecurity: In the context of downsizing in a public sector organisation, sickness absence was half the national average, with evidence that people were substituting presenteeism for absence (Caverley et al, 2007). In the UK, incidences of sickness absence dropped to a record low point during the global financial crisis, then returned to pre-GFC levels once the worst of the crisis was over.

- Absence policies: Chatterji and Tilley (2002) used mathematical modelling to show that policies implemented to reduce absence, such as a reduction in sick pay, were more likely to increase presenteeism, which in turn could lead to more illness and lower productivity. Qualitative data from case studies (Baker-McClearn et al, 2010) found that many interviewees perceived their organisation's sickness absence procedures to compel attendance at work, especially where sick pay was withdrawn, or there was a threat of disciplinary action or dismissal. In one case it was described as 'bullying'. So while absence rates were reduced 'on paper', there were problems with employees attending work sick, suffering stress and anxiety over their absence, not wanting to hit the trigger point and subsequently becoming more unwell. 
- Sickness benefit: The European Foundation for the Improvement of Living and Working Conditions (2013) found that changes in the amount of sickness benefit and how it is paid can have a significant impact on an employee's decision to be present or absent. During the financial crisis, several countries reduced benefits, and this is seen as a key factor driving the declining absenteeism rate (and therefore potential rise in presenteeism) in the various countries.

- Bonuses/incentives: Case study data (Baker-McClearn et al, 2010) found mixed feelings about rewarding good attendance as, while it is nice to be recognised, people felt it could drive presenteeism.

- Working-time arrangements: Evidence from the EU Labour Force Survey (2008) and a study by Bockerman and Laukkanen (2010) suggests that presenteeism is more sensitive to working time arrangements than absenteeism. The following factors increase presenteeism:

- Permanent, full-time work

- Mismatch between desired and actual working hours

- Shift or period work

- Overlong working weeks

- Regular overtime decreases sickness absenteeism, but increases sickness presenteeism.

- Meanwhile, the adoption of three days' paid sickness absence without a certificate and the easing of efficiency demands decrease sickness presenteeism.

This last section on working-time arrangements leads into our final set of organisational drivers relating to the working environment.

\section{Job demands and workplace stress}

This final category of organisational drivers relates more closely to the role and workplace pressures. Here we see some of the mutually reinforcing aspects of tiredness, stress and ill health setting up a vicious circle damaging to employee wellbeing:

- Job demands: In a longitudinal study of staff nurses, Demerouti et al, (2009) found that exhaustion and presenteeism are reciprocal, suggesting that when employees experience exhaustion, they mobilize compensation strategies, which ultimately increases their exhaustion. Specific demands like time pressure, conflicting demands (Aronsson and Gustafsson, 2005), work pressure (European Foundation for the Improvement of Living and Working Conditions, 2013, deadlines to meet, work 
commitments such as meetings and no back up in the department (Caverley et al, 2007) are found to be positively related to presenteeism.

- Peak periods: Qualitative data from Baker-McClearn et al (2010) again fleshes out some of the challenges in two power company case studies. Employees were required to work large amounts of overtime to conduct maintenance for which they earned extra money. Attendance was expected and every employee had a designated role. At these times there was very little absence but following such periods, absence often increased. Presenteeism increased during the time of high pressure, when organisational expectations are much higher, whereas during less pressured times, presenteeism reduces and absenteeism may increase.

Pressure from colleagues and managers: In a study by Ashby and Mahdon (2010) 40 per cent of employees surveyed at AXA PPP perceived pressure from senior managers, line managers and colleagues to come to work when unwell. These people were also more likely to report that their performance was adversely affected by working when unwell.

- Other unfavourable working conditions: Specific conditions found to be positively associated with presenteeism by Eurofound (2012) based on the European Working Conditions Survey are:

- Exposure to work intensity

- Verbal abuse or discrimination

- Handling chemicals

- Awkward postures

- Shift work.

\subsubsection{Personal factors}

At the same time as experiencing organisational pressures, individuals have their own motivations for attending work while ill. Some of these relate to circumstances at home that might be unconducive to rest (Hansen and Andersen, 2008) or not wanting to suffer alone so that people prefer to be with colleagues (Vézina et al, 2011). Others relate to personal financial worries and anxiety about loss of income (Ashby and Mahdon, 2010); others to individual lifestyle factors. Kivimäki et al (2005), for example, found that some people tend to ignore symptoms and avoid seeking medical help. Presumably some are also more resilient and able to tolerate more discomfort than others. 
From an overview of the factors that drive presenteeism we can begin to build a picture of groups that are most at risk.

\subsection{Vulnerable groups}

The full table with studies that identify groups that are vulnerable to presenteeism is attached as Appendix 2. The summary below shows that these cut across the whole organisation in terms of seniority and job role. They include:

- Managers: who feel they should set an example (Ramsey, 2006).

- People with high sickness absence: Being absent due to illness for between one and seven days in a year doubles the probability of having more than 8 days of presenteeism during the same period (Leineweber et al, 2012).

- People with financial problems: Those who were worried a great deal about debt had a significantly higher number of sickness presence days than those without these problems (Ashby and Mahdon, 2010).

- Workaholics: In addition to high levels of presenteeism, they displayed the highest burnout and lowest happiness levels relative to other groups. They also experienced the highest job demands, the poorest job resources, the lowest levels of recovery and performance (Schaufeli et al, 2009).

- Insomniacs: This group has a higher absence rate but pose a risk at work as they have a higher accident rate while driving and a three-fold greater risk of having two or three serious road accidents. They also reported poor self-esteem at work, less job satisfaction, and less efficiency at work, compared with good sleepers (Léger et al, 2006).

- High-skilled white collar workers: Presenteeism was higher among high-skilled white collar workers (around 50 per cent), compared to the other occupational classes (35-38 per cent), a pattern that was observed also for mean days of presenteeism (Eurofound, 2012).

- By level of qualification: Data is mixed with regard to qualifications. Presenteeism increases with qualification level: 57.1 per cent of the qualified employees reported for presenteeism, versus 46.2 per cent with lower qualification levels (EWCS, 2010). Other studies, however, show no difference or a higher risk of sickness presenteeism among workers in lower occupational classes or with lower educational level (Hansen and Andersen, 2008; Aronsson et al, 2000).

- By gender: In one hospital study (Demerouti et al, 2009), men seemed to be more at risk than women but the French part of the European Working Conditions Survey 
(2010), shows no significant difference between men and women. Furthermore gender was not significantly associated with presenteeism in two different studies in Sweden and the Netherlands (Schultz et al 2009). However Bierla et al (2011) found that gender changes the probability of presenteeism: other things being equal, it was lower for women in their study in a French bank. But when the team is mostly composed of men, presenteeism is more important for women. Bockerman and Laukkanen (2010) also look at a range of gender behaviours under different circumstances such as the availability of replacements (see Appendix 2 for more detail).

Being childless: Employees who had recently married or those with one (young) child were less likely to exhibit presenteeism, whereas childless employees were more likely to come to work when sick.

- Older workers: The picture for older workers is not entirely clear. Some of the conditions such as depression, migraine and allergies which are associated with presenteeism decrease with age. Others such as hypertension, heart disease and back pain increase, and others remain flat. In an Australian macroeconomic study Medibank (2011) concluded, 'The impact of Australia's ageing population on productivity losses from presenteeism increases over time but is muted'.

People with unhealthy lifestyle choices: A white paper by the Health Enhancement Research Organisation (HERO, 2013) identifies increased risks for smokers, employees with an unhealthy diet and employees who didn't exercise very much. Excess body weight, elevated blood pressure, and high cholesterol increased the odds of having high presenteeism (percentage of risk is shown in Appendix 2).

- People with poor psychological wellbeing: Presenteeism is significantly associated with self-rated anxiety and psychological wellbeing. Employees with a greater number of days of sickness presence reported higher levels of anxiety and lower levels of psychological wellbeing, whilst those with fewer days of sickness presence reported the converse (Ashby and Mahdon, 2010).

Specific health problems: Various studies identify the risks associated with specific medical conditions. The presence of risk factors, pain and chronic disease, especially chronic depression, dramatically increase the odds of having high presenteeism. Further details are given in Appendix 2.

Some professions/industries: Doctors in particular have been identified as at risk (Rosvold and Bjertness, 2001) but as research progresses it is likely that other groups of workers will also turn out to be vulnerable. The KPMG/Econtech (2011) study identified specific industries - Electricity, gas and water; Culture and recreation services; and Manufacturing - as particularly vulnerable to the losses in labour 
productivity due to presenteeism. (More information on this study is given in Section 4.3.)

\subsection{What can managers take from the dynamic models?}

This section has examined some of the complexities of why people act as they do in organisations. The studies and the diagram above show that the decision to come to work while ill is not simply about how people are feeling on the day. An individual might have any number of the drivers influencing their decision. The problem with all of the studies is that when several factors (independent variables) act on the dependent variable (presenteeism or 'showing up for work when ill') they interact with each other in a range of ways.

David Arnold's (2013) study using the 2010 EWCS data with the single presenteeism question as a dependent variable, shows that the impact of variables changes when the severity of the symptoms is taken into account, while others change with gender or the additional factors of having children, partners, moving jobs, and other factors. The discrepancy in some of the studies highlights this problem. Bierla et al (2011), for example, found that, in a French bank, women seem to behave differently in mixed teams that are predominantly male, so that gender along with other factors become important in particular circumstances and contexts. They suggest this might reflect the 'image of male strength'. It is possible that organisational culture is a key factor here.

Hansen and Andersen (2008) describe some factors as 'double risk factors', which both increase the probability of choosing presence over absence and increase the likelihood of bad health, thus increasing the number of occasions on which the employee must 'decide' between absence and presence. These include time pressure, job insecurity, dissatisfaction with one's family life and over-commitment.

So while there may be some groups that are particularly vulnerable, these people have other demographic characteristics or personal situations which may mitigate or exacerbate their tendency to engage in presenteeism. It is this complexity that managers have to navigate when seeking to understand some of the risk factors within their own teams.

Managers can explore these issues through some key questions under the following headings:

\subsubsection{About the culture}

- Do people often come to work when they are feeling ill in my team? Does my team seem to be more prone to presenteeism than other teams? 
- Is there a pattern of presenteeism behaviour that might be caused by the nature of the work itself (such as duty to customers or professional dedication) or by concern for other team members who would have to shoulder extra workload?

- Do I, as a manager, take sick leave when I need to or do I feel the need to show true grit as a leader?

- Is my team sympathetic towards sick colleagues or is there a tendency to see absence as weakness?

Is there an underlying narrative that values people who 'soldier on'?

\subsubsection{About the policies}

- Do people see absence policies as a measure of control?

- Am I comfortable that absence policies work for the wellbeing of my staff? Do I feel comfortable implementing them?

- Do absence policies feature as a reason for people returning to work early from illness?

Are any staff groups more noticeably affected by absence policies?

\subsubsection{About job strain}

- Are people worried that their work will build up in their absence and no one can help in the meantime?

- Are there tight deadlines, competing pressures or other job strains that mean people feel they have to report for work even when they are ill?

Do people often talk about stress at work?

- Do people regularly have to work late or put in extra hours? 


\subsection{Summary of key findings}

Drivers of presenteeism are multiple, ranging from organisational and team cultures to jobrelated factors and individual differences such as personality and financial circumstances. They arise from seemingly happy cultures with close teamworking, concern for others and high commitment as well as high pressure environments and strict absence policies. The relative dominance of drivers is heavily context dependent although evidence suggests that work factors tend to be more important.

Vulnerable groups cut across the whole organisational spectrum (demographics, personality, seniority, work patterns) but certain groups may be more prevalent in some industries/organisations than others. Key vulnerable groups within a specific organisational context could be prioritised and action plans put in place to tackle underlying drivers.

Preventative programmes that target some of the unhealthy lifestyle issues such as obesity are also worth considering. These might range from offering healthy snacks and meals in the workplace to providing opportunities and incentives for exercise.

It is worth looking at patterns of presenteeism. The Baker-McClearn et al (2010) qualitative studies in two power companies both show employees engaging in 'presenteeism' to cover crises or peaks, then taking absence following these periods. This could reflect a concern for customers and colleagues and general organisational citizenship but, if it is a regular occurrence, the Demerouti study suggests it is linked to stress and burnout. 


\section{Presenteeism and productivity}

This section examines some of the implications for organisations of high presenteeism. First potential benefits and risks are considered, then how to calculate the cost and some of the macroeconomic studies. As one of the biggest contributors to presenteeism, the case of depression and other mental health issues are investigated, followed by an overview of studies showing the impact of a variety of conditions on productivity. Finally, potential mediators are identified from the research.

\subsection{Benefits and risks}

Presenteeism can be both a benefit and a risk and we have already considered positive and negative presenteeism in Section 2.2. On the plus side one would assume presentees will at least contribute something, whilst absentees contribute nothing. Furthermore, being in work is generally considered better for wellbeing. Monneuse (2013), for example, highlights several studies showing that people might prefer to be with their colleagues than suffer solitude and boredom at home, particularly if they are feeling depressed. On the other hand, as presentees struggle on at a decreasing pace, until sometimes finally submitting to an aggravated illness, those that take a complete rest might return to work quickly at full strength and in the meantime also remove any potential risk to colleagues from infection.

Presentees can be over 30 per cent less productive than when they are well (Hemp, 2004) and have the potential in some cases to present a hazard in the workplace or store up trouble for the future. An extreme example reported in January 2014 suggests that a Red Arrows pilot who was killed when his ejector seat triggered accidentally on the ground, may have been suffering from the effects of taking 'Night Nurse', an over-the-counter cold remedy, the night before.

A US survey reported that 56 per cent of employers felt 'presenteeism' was a problem in their organisation; employee burnout and lost productivity were 7.5 times greater with 'presenteeism' than absenteeism (Dixon, 2005). In the American literature a clear focus for employers is the cost of providing healthcare. A recent white paper argues that because leaders are not writing cheques for presenteeism it has not been sufficiently high on the agenda (HERO, 2013). Some of these calculations can lead to extreme conclusions: 
'While estimates vary, some suggest that presenteeism accounts for three-quarters and absenteeism the other one-quarter of the cost of lost employee productivity. If this estimate proves to be accurate, employees physically at work but performing less than optimally would drive three times as much productivity loss as those who don't even show up!

An American survey of 269 CFOs (Chief Financial Officers) by the Integrated Benefits Institute (IBI) (Parry and Molmen, 2002) shows that more than 60 per cent believe there is a strong link between the health of the workforce, its productivity, and the impact on the bottom-line. A follow-up survey of 343 CFOs (Parry and Jinnett, 2006) showed that a large majority believe that ill health impacts the lost productivity associated with presenteeism and absence.

An important study by Baker-McClearn et al (2010), mentioned previously suggests that performance and wellbeing are more closely related to the organisational reaction to presenteeism and absenteeism, rather than the act itself. In other words, people will inevitably get sick and it is up to managers to negotiate the risks and benefits to ensure optimum outcomes for the individual, team and organisational productivity.

\subsection{Calculating the costs of presenteeism}

The impact on productivity clearly depends on both the nature of the affliction and the nature of the job and the calculation is not straightforward. Gosselin and Lauzier (2010), however, argue that while efforts to quantify the incidence and costs of presenteeism are still risky, evaluations to date justify continued interest.

The cost of presenteeism is often considered to include reduced work output, errors on the job and failure to meet quality standards. From a systematic review of the literature in 2009, Schultz et al concluded that although many researchers had attempted to place a dollar value on presenteeism, at that time there was no agreement on the appropriate method for that calculation.

Several of the presenteeism measurement instruments claim to yield results that can be converted into a dollar amount. The general method used is to convert the percentage reduction in productivity into a number of hours per week that an average individual is unproductive. For example, if an employee's presenteeism is 20 per cent, they are considered to be unproductive 8 hours out of the 40-hour work week; that number is multiplied by the average hourly wage and benefits cost for an employee, which is then multiplied by the number of employees with a given health condition. However, it is still unclear if those calculations are meaningful and whether or not an employee experiencing presenteeism is truly zero per cent effective during those hours. 
An expert panel convened by the American College of Occupational and Environmental Medicine recommended that presenteeism measures cover:

- time not on task

quality of work (eg mistakes, peak performance, injury rates)

- quantity of work and personal factors (eg social, mental, physical, emotional) (Loeppke et al 2003).

Ashby and Mahdon (2010) compared sickness levels with actual performance scores and found that employees with higher levels of sickness presence had significantly lower performance scores compared with those with lower levels of sickness presence. Sickness absence (self-reported or recorded by AXA PPP's sickness absence management system) was not significantly related to this performance measure.

The Centre for Mental Health recommends that 'performance measures should be in place which are sophisticated enough to pick up any significant change in individual performance and these measures should be monitored alongside sickness absence'.

\subsection{Macroeconomics}

In 2011, Medibank Private commissioned KPMG Econtech to identify the macroeconomic impact of presenteeism on the Australian workforce and the wider economy. The study estimated the productivity loss from 12 common medical conditions by applying data on the prevalence of each condition in the Australian working population to international estimates of the on-the-job productivity losses from each condition. Comparing two scenarios (firstly where presenteeism is prevalent and secondly where there is no presenteeism) the headline findings reported were:

- The overall cost of presenteeism to the Australian economy in 2009/10 was estimated at $\$ 34.1$ billion (nearly four times the cost of absenteeism).

- Presenteeism equated to a 2.7 per cent decrease in 2010 GDP.

- On average, 6.5 working days of productivity are lost per employee annually as a result of presenteeism.

The study also examined the projected effects of presenteeism in 2050 taking into account age-specific prevalence rates of illness and demographic change. In 2050, the total cost of presenteeism is estimated to rise to $\$ 35.8$ billion with a decrease in GDP of 2.8 per cent. With the changing demographic and an older workforce the most common types of conditions affecting workers by 2050, are projected to be: 
arthritis

- heart disease

nypertension

- back, neck or spinal problems.

Figure 4.1 shows the percentage contribution at the time of the report that each medical condition makes to the overall productivity loss caused by presenteeism. They found that currently the biggest contributors are depression (21 per cent), allergies (17 per cent), hypertension (13 per cent) and diabetes (12 per cent).

\section{Figure 4.1: Contribution of Medical Conditions to Overall Productivity Loss Caused by Presenteeism}

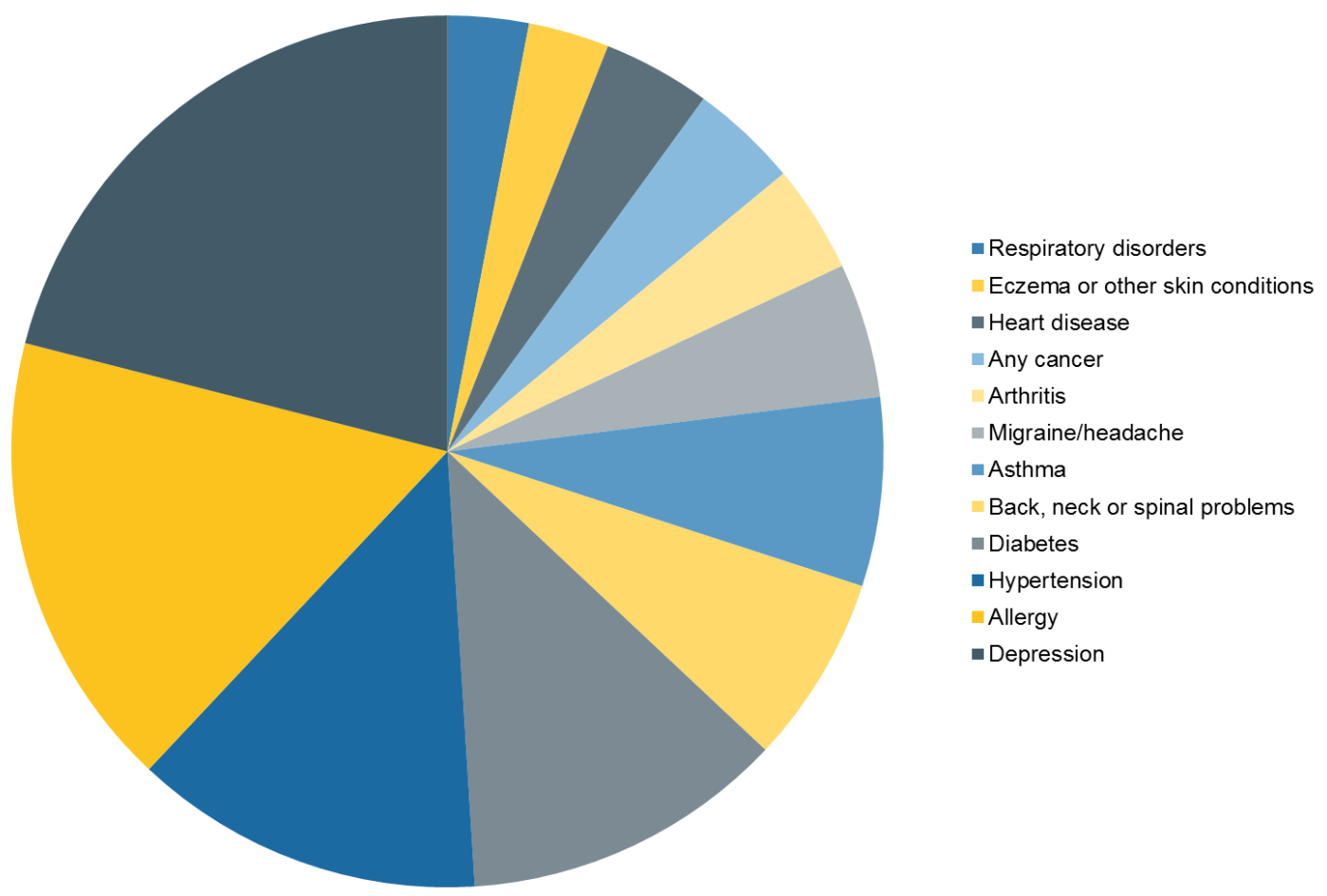

Source: KPMG Econtech, 2011

An average productivity loss of 2.6 per cent per worker corresponds to a loss of 6.75 working days per worker per year for an average Australian worker, which equates to Aus $\$ 1,615$ per employee per year for the top 10 health conditions in 2009-2010.

The KPMG Econtech study goes on to highlight the impact of productivity loss throughout the economy:

'Presenteeism causes direct labour productivity losses to employers. These direct impacts then filter through the economy, causing changes to capital investment and other impacts to 
upstream and downstream industries. These other impacts are the indirect impacts of presenteeism.'

While the KPMG study has not been analysed here from an economist's perspective, the important message for this current review is that presenteeism is being taken seriously at the national level as having wide-ranging implications for organisations and the economy as a whole. Figure 4.2 shows the KPMG/Econtech's calculations on the impact on various industries' production that is attributable to labour productivity losses stemming from presenteeism. The electricity, gas and water industry shows the largest impact of 5.3 per cent decrease in production when compared to the 'No Presenteeism' Scenario.

\section{Figure 4.2: Impact of Presenteeism on Industry Production}

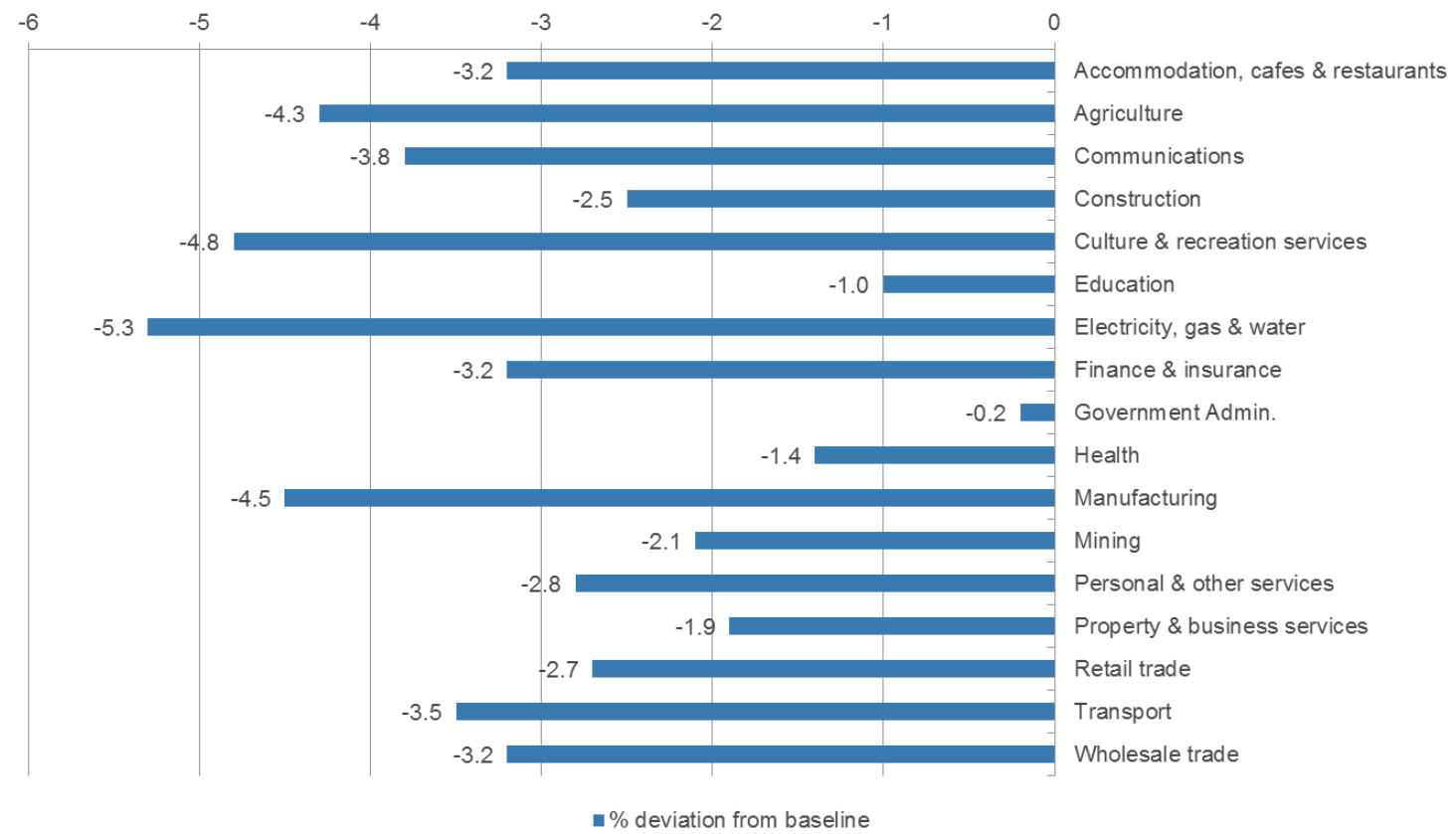

Studies in the US show similar concerns about the impact on a national scale. LevinEpstein (2005) maintains that according to American studies, the costs of presenteeism amount to an annual total of US $\$ 180$ billion.

Some interest, of course, is generated by suppliers of wellness programmes with the aim of generating business, so caution should be exercised with regard to cost estimates. Several projects, currently under way, are the result of a partnership of insurance companies, educational institutions and others with a vested interest in quantifying the human and ROI value of wellness programmes. 
Klachefsky (2012) from the Standard Insurance Company pulls together the following data:

- On-the-job losses from presenteeism are 60 per cent of the total cost of worker illnesses, which exceeds what companies are spending on medical, disability and absenteeism (Lang, 2004).

- For 10 conditions studied, presenteeism drove from 18-61 per cent of total costs (the total costs are split into health care, pharmacy, absence and presenteeism showing that for some conditions the loss of productivity through presenteeism has a disproportionate impact) (Goetzel et al, 2004).

- In a survey of 29,000 workers, presenteeism accounted for 1.32 hours per week (66 per cent) of lost time ... absenteeism accounted for the rest (Stewart et al, 2003).

\subsection{The case of depression and mental health}

Of all the illnesses that impact productivity at work, depression probably merits particular attention due to its prevalence (according to Layard (2013), it accounts for half of all disability of people of working age, ie as much as the combined effects of back pain, heart pain, pulmonary problems, diabetes and cancer and is frequently co-morbid with other illnesses) and because it is often hidden and stigmatised. Figure 4.1 above shows depression as the biggest contributor to productivity loss at work in Australia.

Levels of presenteeism are increasing across Europe too. Figure 4.3 compares the rise of presenteeism for those with a severe mental health disorder, a moderate mental health disorder and no mental health disorder. 


\section{Figure 4.3: Presenteeism has increased among all groups of the population}

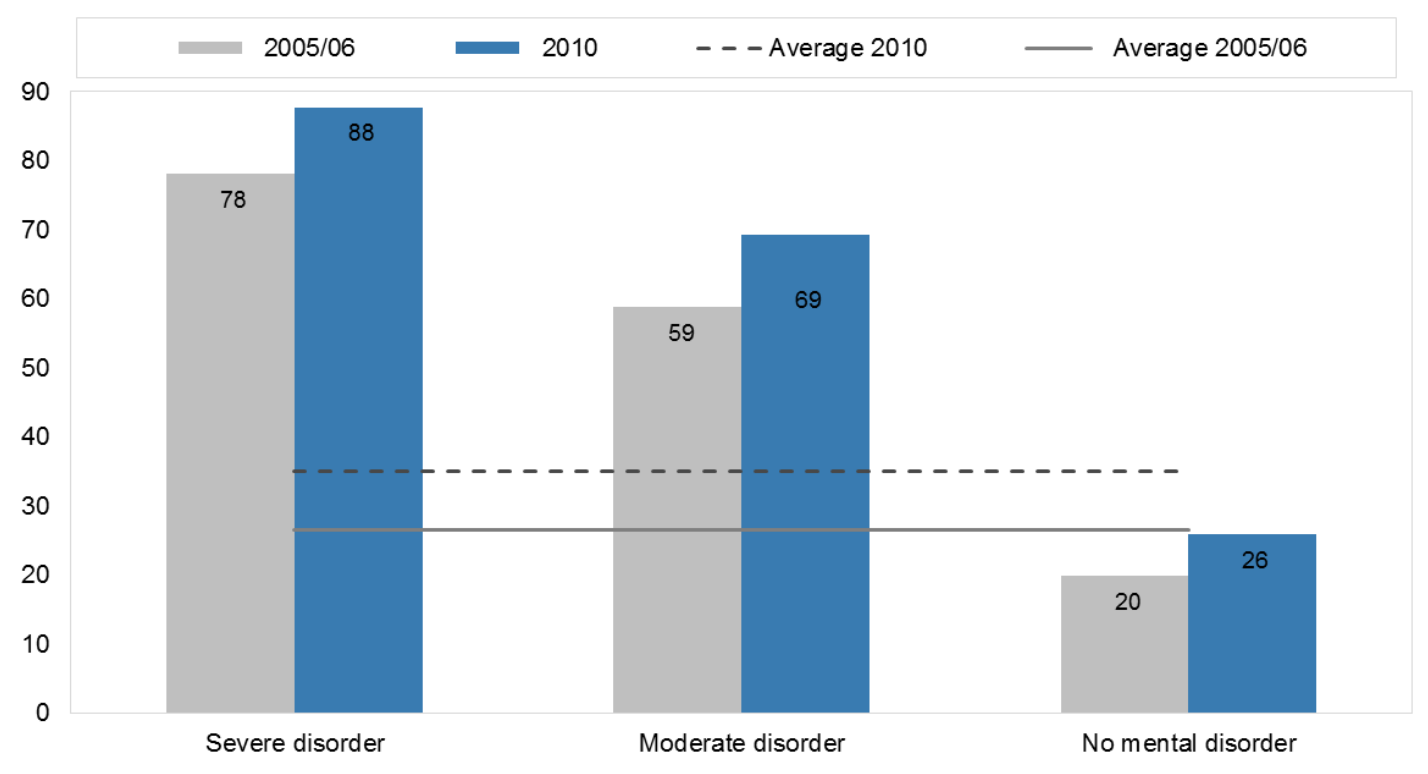

Notes: Percentage of workers who were not absent in the past four weeks but who accomplished less than they would like as a result of either an emotional or a physical health problem, average of 21 European OECD countries, 2005 and 2010

Source: OECD, 2012

And while absenteeism and presenteeism levels vary by country, mental health differentials are consistent (Table 4.1).

The OECD (2012) suggests that treatment is a prerequisite to better employment outcomes for people with a mental disorder but found that across OECD countries nearly half of those with a severe mental disorder and over 70 per cent of those with a moderate mental disorder do not receive any treatment for their illness. They also report that worker productivity loss is strongly driven by poor mental health:

'For workers with common mental disorders, reduced productivity while at work is the biggest issue, potentially with considerable and typically hidden spill over on co-workers. Added to this, presenteeism seems to have increased in all countries for all occupations, and more so for workers with a mental disorder.' $p 77$

Sickness absence frequency and average duration both increase for those with mental disorders but the greatest disparity between those with no mental disorder and those with a severe disorder is in the incidence of presenteeism. Those with a mental disorder, when asked about productivity over the preceding four weeks, were more than three times as likely as those with no disorder, to accomplish less than they would like to (see Table 4.1).

Alternative measures on a range of indicators from the 2005 Eurobarometer confirm the findings (see Figure 4.4). 


\section{Table 4.1: Absenteeism and presenteeism levels vary by country but mental health differentials are consistent}

\begin{tabular}{|c|c|c|c|c|c|c|c|c|}
\hline & \multicolumn{4}{|c|}{$\begin{array}{c}\text { Panel A. Sickness absence incidence } \\
\text { Percentage of persons } \\
\text { who have been absent from work }\end{array}$} & $\begin{array}{r}\text { Percentage o } \\
\text { than } t\end{array}$ & $\begin{array}{l}\text { B. Preser } \\
\text { vho were } n \\
\text { like as a re }\end{array}$ & $\begin{array}{l}\text { idence } \\
\text { ut who acco } \\
\text { emotional pr }\end{array}$ & d less \\
\hline & $\begin{array}{l}\text { Severe } \\
\text { disorder }\end{array}$ & $\begin{array}{l}\text { Moderate } \\
\text { disorder }\end{array}$ & $\begin{array}{l}\text { No mental } \\
\text { disorder }\end{array}$ & All & $\begin{array}{l}\text { Severe } \\
\text { disorder }\end{array}$ & $\begin{array}{l}\text { Moderate } \\
\text { disorder }\end{array}$ & $\begin{array}{l}\text { No mental } \\
\text { disorder }\end{array}$ & All \\
\hline Austria & 50 & 38 & 19 & 23 & 100 & 78 & 23 & 34 \\
\hline Belgium & 65 & 37 & 17 & 22 & 86 & 81 & 25 & 37 \\
\hline Denmark & 50 & 35 & 26 & 28 & 88 & 73 & 35 & 42 \\
\hline Netherlands & 72 & 39 & 25 & 28 & 95 & 69 & 25 & 34 \\
\hline Sweden & 44 & 51 & 29 & 33 & 84 & 72 & 25 & 35 \\
\hline UK & 42 & 27 & 20 & 22 & 83 & 68 & 24 & 32 \\
\hline Average $^{a}$ & 42 & 28 & 19 & 21 & 88 & 69 & 26 & 35 \\
\hline Australia & 30 & 17 & 10 & 11 & .. & .. & .. & .. \\
\hline Norway & 11 & 7 & 6 & 7 & .. & .. & .. & .. \\
\hline US & 17 & 10 & 6 & 7 & .. & .. & .. & .. \\
\hline
\end{tabular}

Notes: Absenteeism and presenteeism (in percentage), by country and severity of mental disorder, 2010 or latest year available

Absence is defined as: absence in the last four weeks for European OECD countries, absence in the last two weeks in Australia, absence in the last week in Norway and absent for ten days or more in the last year in the United States.

a) The average is based on all countries covered in the Eurobarometer survey. 


\section{Figure 4.4: Absenteeism and presenteeism both increase sharply with poorer mental health}

Panel A. Sickness absence incidence

Percentage of persons who have been absent from work

in the past four weeks (apart from holidays)

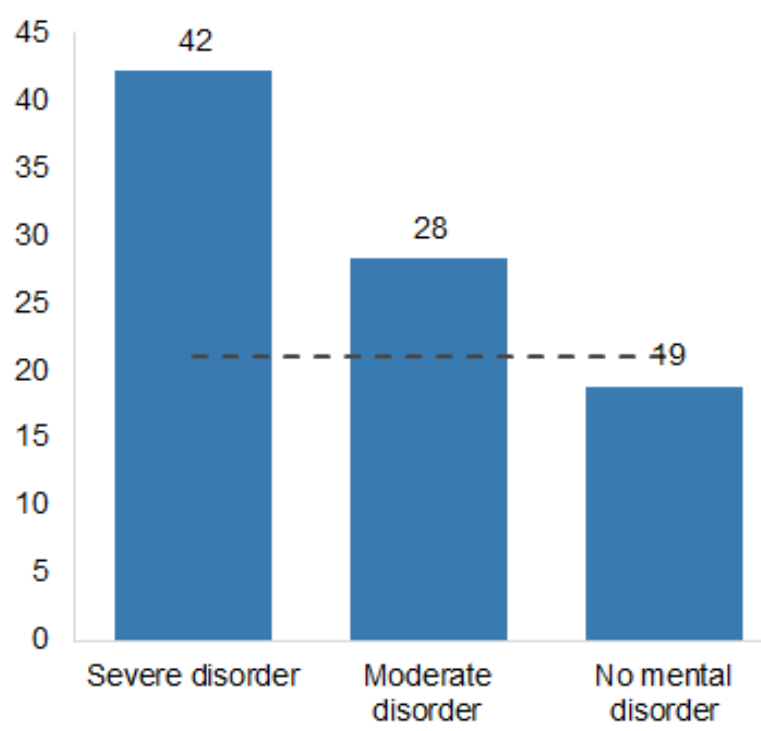

Panel B. Average duration of sickness absence

Average number of days absent from work in the past

four weeks (of those who have been absent)

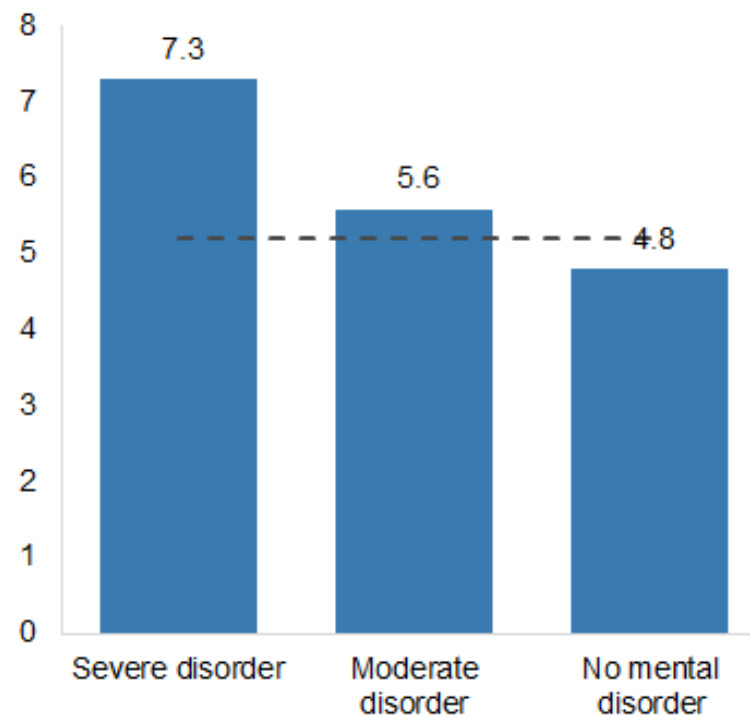

Panel C. Presenteeism incidence

Percentage of workers not absent in the past four weeks but who accomplished less than they would like as a result of an emotional or physical health problem

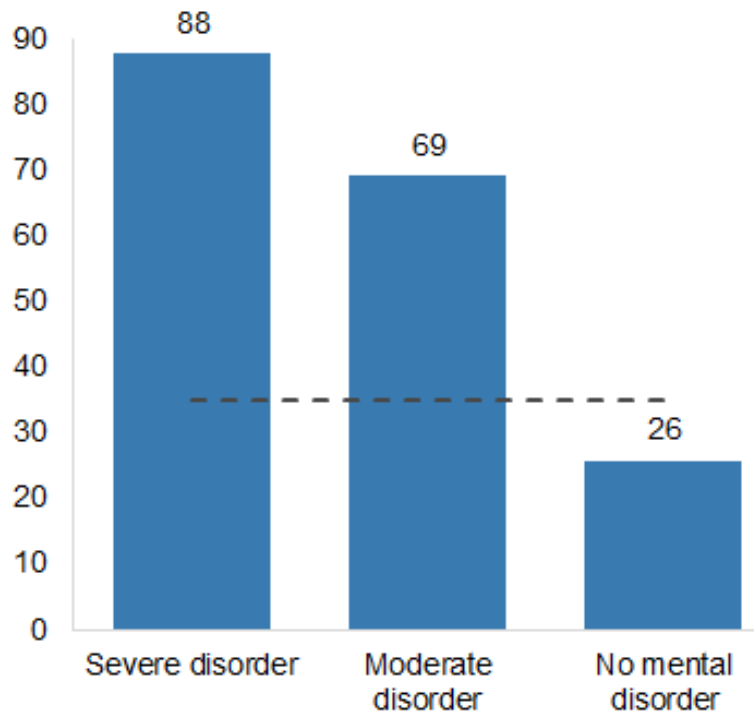

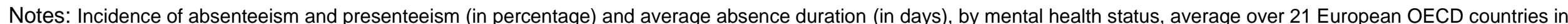
2010

Note: Averages are represented by dashed lines. 


\section{Figure 4.5: Alternative measures of productivity loss}

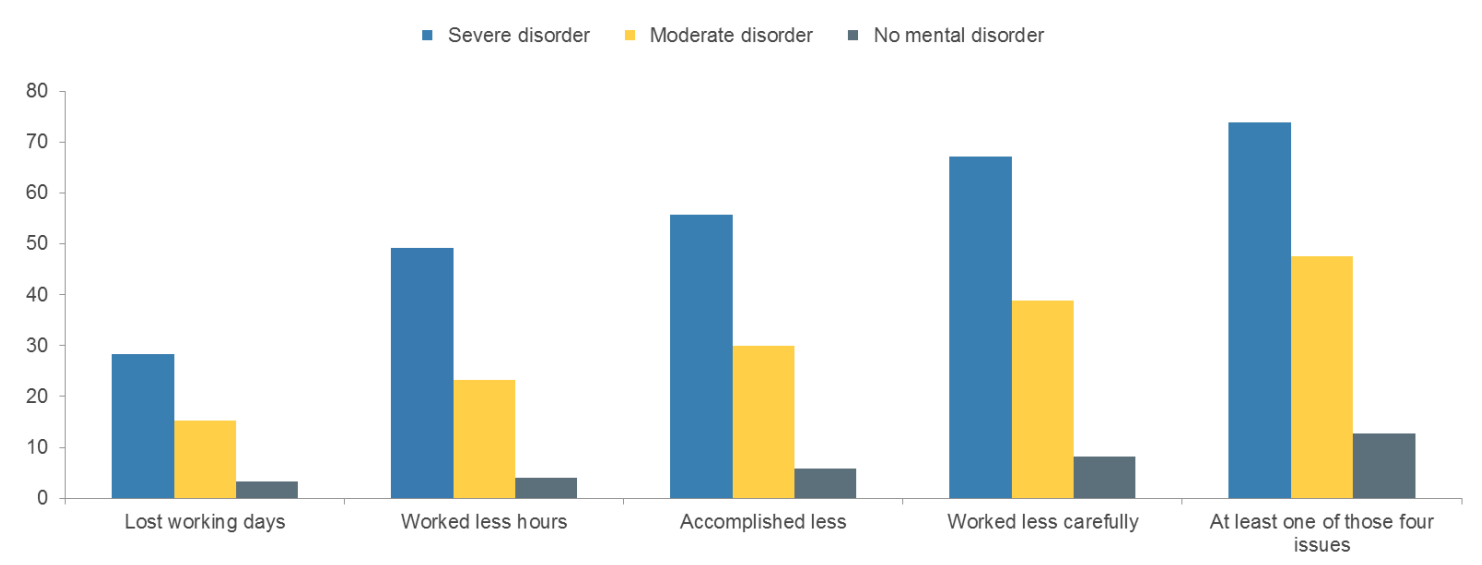

Notes: Percentage of workers who faced various productivity losses in the past four weeks, as a result of an emotional problem, by severity of mental disorder, average of 21 European OECD countries, 2005

Source: OECD, 2012

One finding shown in Figure 4.5 above that might warrant further investigation by HR, Occupational Health or line managers is that that those with mental disorders report working less carefully, which in some roles may have safety implications.

According to Layard (2013), mental health affects earnings, educational success, employment and physical health. In advanced countries mental health problems are the main cause of illness of working age people, accounting for over one-third of disability and absenteeism. They can also cause or exacerbate physical illness. One per cent of work-hours are lost due to absenteeism and on top of that the cost of underperformance, based on self-reports, may add another one to two per cent to the direct output costs of mental illness. Layard argues that while effective treatments are available, there is a world-wide under-treatment of mental health problems. He highlights that in 17 out of 19 OECD countries the incidence of work-related mental problems is increasing and that surveys of individuals show that the worst time in their day is when they are in the presence of their line manager. He argues for better job design and a more pro-active way of handling absence.

The OECD also suggests that while unemployment and particularly long-term unemployment is bad for mental health, not all jobs are good for mental health. It concludes:

'Jobs which are psychologically demanding but leaving limited decision latitude, a situation commonly referred to as job strain, have a significant negative impact on the worker's mental health. And job strain has increased over time in most occupations. The quality of employment matters and one of the biggest factors in this regard is good management, ie a 
manager who supports the worker, gives adequate feedback, recognises the work effort and talks to the employee.' $p 80$

Munir et al (2009) highlight the particular problems for people with depression returning to the workplace. They found that participants with depression found it more difficult to adjust back to work than any other group.

\subsubsection{Recommendations for supporting presentees with mental health problems}

- The role of line managers is pivotal in making work adjustments and providing support to returning employees and they should work closely with other stakeholders such as $\mathrm{OH}$ practitioners, HR professionals and unions (Munir et al, 2009).

- The OECD calls for better training and information for people such as managers who work outside the mental health sphere.

- Identify those employees returning to work who are at risk of depression as a key policy and part of the risk assessment framework. In the UK this is already in place with regards to UK legislation on general health and safety at work, and the HSE management standards for work-related stress (Munir et al, 2009).

- In view of the widespread under-treatment of mental illness (and equally widespread treatment by non-specialists), employers and $\mathrm{OH}$ experts should be closely involved in ensuring that employees access all treatment available in line with clinical guidelines.

- Employers should provide employees returning to work following depression with stress management training to help reduce the risk of depression and anxiety (Munir et al, 2009).

- Line managers should be aware that some roles may be less suitable for people with mental disorders in the light of findings that they self-report that they sometimes work less carefully because of their illness. This might involve adjusting duties.

- Managers also need to monitor the level of job strain and have regular and frank discussions with affected employees to ensure they are not suffering unnecessary stress.

\subsubsection{Seasonal affective disorder (SAD)}

In addition to full blown depression, a survey of over 1,000 UK office workers by Epson (2013), has found that 9.6 million work days are lost each year as a result of employees 
suffering from the 'winter blues' or SAD. The survey, finds that 20 per cent of British workers admit to calling in sick because of the winter blues and, on average, those that do call in sick, take off four days a year because of the condition. The results highlighted the ways in which the winter months impact UK office workers, with 60 per cent stating that it makes it harder to get out of bed. This was closely followed by decreased levels of motivation (59 per cent), depression (58 per cent) and greater susceptibility to illness (52 per cent). These symptoms come in light of the finding that almost half (48 per cent) of workers rarely or never see sunlight on the way to work during the winter months.

\subsection{Fatigue}

While lack of sleep is not normally classed as an illness, prolonged insomnia might be a symptom of other health conditions or the result of stress, shift patterns or other workrelated activity. According to Harvard Professor, Charles Czeisler (Czeisler and Fryer, 2006), sleep deprivation among employees poses various risks to companies:

'With too little sleep, people do things that no CEO in his or her right mind would allow. All over the world, people are running heavy and dangerous machinery or guarding secure sites and buildings while they're exhausted. Otherwise intelligent, well-mannered managers do all kinds of things they'd never do if they were rested - they may get angry at employees, make unsound decisions that affect the future of their companies, and give muddled presentations before their colleagues, customers, the press, or shareholders.'

Fatigue and burnout are worthy of particular attention as they seem to set up vicious cycles of poor productivity and increased stress or anxiety leading potentially to further sleep disorders (see studies in Appendix 2 and Appendix 3). Insomniacs (Léger et al, 2006) had higher accident rates while driving and a three-fold greater risk of having two or three serious road accidents. They also reported poor self-esteem at work, less job satisfaction, and less efficiency at work, compared with good sleepers. A cross-cultural study of British and Chinese workers (Lu et al, 2013) found that supervisor support buffered the negative impact of presenteeism on exhaustion.

The Rio Tinto example below shows how fatigue was identified as a specific organisational issue and the measures taken to address it.

Rio Tinto, W Australia (Bennet, 2012)

Rio Tinto was concerned about the impact of fatigue on productivity in their mining operations. Their 2009 Employee Engagement Survey revealed that many employees were dissatisfied with the management of fatigue in RT's Iron Ore operations. Supporting data came from an Internal Audit of Fitness for Work in 2008. In 2010 a Fatigue Management Project Team was set up, charged with understanding the issues surrounding fatigue and devising appropriate recommendations/solutions for the Iron Ore Executive Committee. Solutions were piloted and then rolled out across the Pilbara Operations. 


\section{Key findings were:}

- Workers with a two week on, two week off pattern were starting with a sleep debt following a 5.30am flight out of Perth. This was exacerbated by early shift starts.

- There was limited education and knowledge about fatigue and its impact at Management, Supervisor and Operator level.

- Data analysis highlighted that fatigue increased over the night shifts, leaving employees at an effectiveness level of around 63 per cent (worse than a BAC of 0.08).

- When they arrived back in Perth people were commuting home with a reaction speed equivalent to twice the legal alcohol level and required four days of rest to recover to normal.

Recommendations were made to adjust flight times and shift patterns and to improve training and awareness for all staff.

\subsection{Workplace stress}

Stress presents another definitional problem and Monneuse (2013) points out that doctors vary in their diagnoses and recommendations about taking time off work.

A study by Gilbreath and Karimi (2012) investigates 'job-stress-related presenteeism' (a form of psychological strain caused by job stress) and specifically the impact of supervisor behaviour and role modelling.

They found that job stress and presenteeism were positively correlated and that negative supervisor behaviours had the strongest associations with employee job-stress-related presenteeism. These were:

- fails to properly monitor and manage group dynamics

- makes decisions that affect employees without seeking their input

- shows disinterest in employees' ideas and projects

is easily threatened by competent employees

remains aloof from employees

- ignores employees' suggestions

tends to be guarded (eg not open) in his/her communication.

The supervisor behaviour with the highest negative correlation with employee presenteeism was 'helps employees keep work in perspective'. 


\subsection{Overview of health factors that impact productivity}

Numerous studies have shown productivity loss from presenteeism across a range of illnesses and job roles. While studies attempt to isolate various conditions it is important to remember that many of these are co-morbid so that, for example, people suffering from general poor health may also have pain and possibly also poor mental health. The table of studies is included as Appendix 3 but some of the key findings are summarised below:

- General poor worker health: The American Integrated Benefits Institute suggests poor worker health and its drag on productivity costs employers $\$ 576$ billion annually. Of that amount, 39 per cent or $\$ 227$ billion results from lost productivity tied to poor worker health that drives absences and presenteeism.

- Pain: In one case study over four weeks, it was estimated that those in pain lost 3.14 days of work due to presenteeism and 0.84 days due to absenteeism, versus 0.29 and 0.06 days for the healthy comparison group. Musculoskeletal and 'mental and nervous' problems topped the list (Allen et al, 2005).

- Depression: Workers with depression reported significantly more lost productive time than those without. Mild to moderate symptoms of depression were found to be associated with poor work and repeated spells of certified sick leave. A combination of poor work adjustments, minimal line manager support and lack of early psychological intervention appeared to have a significant negative impact on employees. Those returning to work following an episode of depression found it more difficult to adjust back to work compared with those returning to work with other illnesses and line managers and colleagues had little understanding of depression (Munir et al, 2009).

- Stress: According to an Australian study by Medibank Private (2008) workplace stress is responsible for a loss of 2.14 working days per employee annually as a result of presenteeism, which equated to a cost of $\$ 533$ per employee annually.

- Burnout: Presenteeism gives rise to feelings of burnout because of insufficient recovery. In turn, burnout leads to an accumulation of workload and decreases the energy to cope, causing a more accentuated presenteeism (Demerouti et al, 2009).

Storing up problems for the future: Presenteeism can exacerbate existing conditions and delay recovery (Aronsson and Gustafsson, 2005) and increase the likelihood of future sick leave (Bergström et al, 2009). A three-year follow-up of British civil servants who were never sick during the period, showed an increased risk of serious coronary events and poorer health compared to others. Seventeen per cent of unhealthy employees took no absence during the three-year follow-up. Their 
incidence of serious coronary events was twice as high as that of the unhealthy employees with moderate levels of sickness absenteeism (Kivimäki et al, 2005).

- Fatigue: Long work hours may contribute to chronic sleep loss, which may in turn result in work impairment. Risk for sleep disorders substantially increases the likelihood of negative work outcomes, including occupational accidents, absenteeism and presenteeism (Swanson et al, 2011).

- Migraine: In 1997 migraine headaches were estimated to be responsible for $\$ 12$ billion of lost productivity annually in the United States, with 60 to 70 per cent of this cost the result of impaired performance while at work (Schwartz et al, 1997).

- 10 Chronic Health conditions: A study of employees at the Dow Chemical Company calculated the annual total costs (including medical, pharmacy, absenteeism and presenteeism) relating to allergies, arthritis, asthma, back/neck disorder, breathing disorder, depression, diabetes, heart or circulatory problems, migraines and stomach or bowel disorders. For each health condition, the presenteeism cost was the major component of cost, exceeding medical care, pharmacy costs and absence costs. The company estimated that lost productivity due to health was equal to 6.8 per cent of the total labour costs of their US workforce in 2002 (Collins et al, 2005).

While health problems might be expected to reduce productivity, there are also factors that seem to mitigate the loss.

\subsection{Potential mediators of productivity loss}

Studies relating to factors mediating productivity loss are shown in Appendix 3 and key points are summarised below.

Supervisor support: Lu et al (2013) found that supervisor support acted as a buffer between presenteeism and exhaustion (see Section 4.5 above).

- Being able to make work adjustment: Employees who were unable to adjust their work around their health condition were more likely than those who could, to report that their performance was adversely affected when working while unwell (Ashby and Mahdon, 2010).

- Health interventions: Hemp (2004) suggests that relatively small investments in screening, treatment and education would reap substantial productivity gains.

- Organisational support for healthy lifestyles: The Health Enhancement Research Organization found that employees who reported it was difficult to eat healthily at work were 93 per cent more likely to have high presenteeism. Those who reported 
that their employer had little interest in supporting employee efforts to becoming more physically active were 123 per cent more likely to have high presenteeism. Those who indicated that their employer was not supportive in helping them become emotionally healthy were 320 per cent more likely to have high presenteeism (HERO, 2013).

\subsection{Summary of key findings}

There is a fine line between 'good' and 'bad' presenteeism, where an individual benefits from the company of colleagues but risks exacerbating a condition. Line managers should seek to understand the underlying drivers and provide work adjustments where necessary to optimise performance. They also need to be aware of health and safety risks where people might be affected by medication or mental disorders, where many report working less carefully.

Putting a monetary value on presenteeism remains risky and complex but the evidence suggests it is worth taking seriously and macro studies suggest that substantial costs are felt throughout the economy.

Depression is worth special attention due to its prevalence and lack of visibility. Line managers are often ill equipped to deal with this form of illness.

Fatigue is also worth special attention because of the mutually reinforcing impact of presenteeism and fatigue. The Rio Tinto case, for example identifies the specific causes of fatigue and its impact on productivity and personal health and safety.

Potential mediators are important and supervisor support and role-modelling is a consistent theme throughout the presenteeism studies. 


\section{Measurement, reporting and benchmarking}

The measurement and reporting of presenteeism is clearly more difficult than that of absenteeism and the topic is still relatively new in terms of organisational interest. This section identifies common problems in measurement and discusses some of the measures in use and factors to consider when choosing a measure.

\subsection{Common measurement problems}

Following a systematic review of the literature in which 70 per cent of studies were excluded due to concerns of bias in the measurement of presenteeism, Cancelliere et al (2011) recommend that future research would benefit from standard presenteeism metrics and studies conducted across a broad range of workplace settings.

Measuring the impact of presenteeism on productivity is even more difficult. Schultz et al's (2009) literature review showed that it is unclear whether popular measurement instruments measure the same productivity loss between job classification or industry sectors. This makes benchmarking across industries and sectors currently impractical.

Measurement difficulties relate to both the frequency of presenteeism and its impact on productivity. Some of the difficulties with measurement and comparability are:

At what point is someone a 'presentee'? Most people will feel 'off colour' or 'under par' at some point while they are working, without necessarily needing to be absent. A typical measurement item is subjective, for example:

'Has it happened over the previous 12 months that you have gone to work despite feeling that you really should have taken sick leave because of your state of health?'

Most researchers base 'presenteeism' on at least two days a year of presence while ill (Aronsson et al, 2000; Aronsson and Gustafsson, 2005; Elstad and Vabo, 2008;

Bergström et al, 2009). Subjects who report not having been sick in the previous year are normally excluded, along with those who have high absence (probably more than 70 days in the year). There are, however, variations across studies in the number of 
days of attendance while sick taken into account that make direct comparisons difficult.

- Self-reported data: Most measures rely solely on the respondents' own perception of health and their evaluation of the legitimacy of taking sick leave in a given instance. There is rarely an objective judgement of their health status. Studies, therefore, tend to suffer from common method variance stemming from asking people to self-diagnose their health and then estimate its impact on their own productivity.

- Retrospective frequency measures: These rely on recall such as looking back over the previous year or shorter periods of time.

- Cross-sectional versus longitudinal data: Cross-sectional data (sometimes called oneshot because it provides a snapshot rather than a picture over time) cannot show causality or the direction of the relationship between the independent variables proposed and presenteeism, because of the possible effect of reverse causality inflating the associations (for example, people who consider their work environment bad may report more presenteeism than they actually had).

- Variety of measurement instruments: Some instruments address only specific conditions, some address a range of conditions, and others address all conditions. Furthermore, there are two streams of research (health and organisation) and they use different approaches to measurement. According to Johns (2010) they neither describe illnesses similarly nor share a standard outcome metric.

What constitutes full productivity? It is difficult to assess a percentage productivity drop unless closely task related such as production output. In knowledge or creative industries this is much more challenging.

Work loss instruments: These are better at reflecting within-employee differences rather than between-employee differences which can be accounted for by many different variables such as motivation.

- Measurement differences across countries: When national pharmacoeconomic guidelines are compared, different recommendations are identified on how to identify, measure and value lost productivity, leading to difficulties when comparing lost productivity estimates across countries. From a transferability point of view, the question arises of whether differences between countries regarding lost productivity are the result of using different calculation methods (methodological differences) or of other between-country differences (Knies et al, 2012).

- Different welfare regimes: A lot of studies are in Scandinavia and may not generalise to other welfare regimes that are less generous. 


\subsection{Review of measures}

In a systematic review of measures, Mattke et al (2007) identify three ways of thinking about presenteeism:

1. Assessment of perceived impairment: by asking employees how much their illnesses hinder them in performing common mental, physical, and interpersonal activities and in meeting job demands. Tools that use this approach include the Health and Productivity Questionnaire, Health and Work Questionnaire, Stanford Presenteeism Scale, Work Limitations Questionnaire, and Work Productivity and Activity Impairment Questionnaire.

2. Comparative productivity, performance, and efficiency: (comparisons with others and with one's norm) these have three main advantages over number one above for expressing presenteeism as a single meaningful number:

- The attempt to benchmark one's perceived performance provides a reference against which loss can be measured although it remains dependent on self-report data.

- When based on a 10-point performance scale or a percentage scale, the results can be incorporated more easily into a monetisation formula than agreements or disagreements with statements about perceived impairment.

- Attempts have been made to validate employees' self-reported performance evaluation by comparing them with their supervisors' assessments.

3. Estimation of unproductive time while at work: eg the Work Productivity Short Inventory asks employees to estimate how many unproductive hours they spent at work during the recall period. Although this approach would lead to the easiest monetisation, Mattke et al (2007) found no examples showing that employees can accurately transform their perceived impairments into a temporal measure.

While Mattke et al (2007) agree that most instruments have accepted validity, the biggest problem remains the lack of an established and validated method to derive monetary estimates of the cost of lost productivity.

\subsubsection{Estimating the extent of presenteeism from absence data}

From a measurement perspective organisations might see the challenges of collecting and evaluating presenteeism data as too daunting. The number of absence days is usually freely available while presenteeism is often invisible. However, the difficulty of measuring presenteeism should not be taken as an indication that it is less important. 
Huver et al (2012) have tested a quantitative tool designed to measure presenteeism based on employee absence data. Using a zero-inflated negative binomial model (ZIMB) and longitudinal data covering 30 years with demographic variables, job-related variables and absence data for each employee from 3,600 employees in a French hospital, they claim to have captured the phenomenon of presenteeism. The statistical technique starts from two assumptions:

- There is a standard or average absence level, corresponding to normal behaviour. In comparison, some groups have an abnormally low absence level (presenteeism) and another group an abnormally high absence level (absenteeism).

- Longitudinal data can be used to look at outcomes over time for employees used to attending work despite being sick, (ie past absence records are characterised by very low or zero values) to explore the links between presenteeism and further sickness absence.

The model computes presenteeism probability from absence data using distribution principles such as illness tending to increase with age or there being no reason for those in non-permanent roles having less sickness than permanent staff. Their findings are in line with and support other studies that have identified 'at risk' groups such as managers and non-permanent staff, and this looks a promising way to assess the extent of presenteeism in an organisation using existing data. One word of caution, however, is that the two parts of the model represent either sickness absence or presence behaviour and does not allow for a distinction between negative/positive absenteeism and presenteeism discussed in Section 2.2. It is simply a statistical technique with large datasets that can identify patterns of behaviours of certain groups of people which would not normally be expected.

This technique, for example, might be appropriate to explore the extent of presenteeism and as a basis for a more in-depth exploration of the drivers of presenteeism.

\subsubsection{Examples of measures of presenteeism}

In the 'European Working Conditions Survey' (EWCS) conducted in 2010 of about 40,000 respondents in 34 countries, presenteeism is captured through the following question: 'Over the past 12 months did you work when you were sick?' To that question, 40 per cent of all respondents answered positively. While a single question can provide a simple assessment of frequency, scales are more appropriate to ensure consistency and validity.

\section{Stanford Presenteeism Scale (SPS-6): Health Status and Employee Productivity}

One of the most well-known measures is the Stanford Presenteeism Scale, originally a 34item scale reduced down to six items (the SPS-6). Work experiences are described for the 
past month and ('health problem') can be substituted by descriptors such as back pain, cardiovascular problem, stomach problems or illness. A five-point scale is used for responses ranging from strongly disagree to strongly agree.

1. Because of my (health problem), the stresses of my job were much harder to handle.

2. Despite having my (health problem), I was able to finish hard tasks in my work.

3. My (health problem) distracted me from taking pleasure in my work.

4. I felt hopeless about finishing certain work tasks, due to my (health problem).

5. At work I was able to focus on achieving my goals despite my (health problem).

6. Despite having my (health problem), I felt energetic enough to complete all my work.

The research on the SPS-6 (Koopman et al, 2002) shows it has good validity and internal consistency. It is able to capture two dimensions of presenteeism: work process (avoiding distractions) and work outcome (completing work). It also lacks a strong correlation with Job Stress and Job Satisfaction suggesting that presenteeism is a distinct concept rather than simply another name for stress or dissatisfaction at work. The scale is considered suitable for use across worksites and varying demographic characteristics.

\section{World Health Organization Health and Work Performance Questionnaire (HPQ)}

The HPQ is a brief self-report questionnaire that obtains three types of information: screening information about the prevalence and treatment of commonly occurring health problems; information about three types of workplace consequences (sickness absence, presenteeism, and critical incidents); and basic demographic information. Specific items of the HPQ can be used to score presenteeism (or a combination of presenteeism and absenteeism). Presenteeism is conceptualised as a measure of actual performance in relation to possible performance. Instructions are available from Harvard Medical School and the WHO with regard to the use and scoring of these items although there are disadvantages when not using the full HPQ. Firstly additional questions in the HPQ allow imputations and consistency checks to be made for questions that are most often left missing in the short absenteeism and presenteeism question series. It also includes additional memory priming questions that improve the accuracy of report. Use of the full HPQ makes it possible to have the data included in the HPQ master dataset, in which case more complex scoring rules can be used to code presenteeism than the simple scaling methods for the separate items. These more complex rules use regression-based methods to calibrate scores on the presenteeism scales to objective measures obtained in several archival calibration studies. 
Despite these limitations, the short HPQ absenteeism and presenteeism questionnaire is reported to be quite useful in providing a quick assessment of lost work performance in a workplace sample.

\section{Job-stress-related presenteeism}

Some scales focus on specific health issues. The scale by Gilbreath and Frew (2008) (in Gilbreath and Karimi, 2012) focuses on work-related stress with six items on a five-point scale ranging from all the time (5) to never (1).

1. I'm unable to concentrate on my job because of work-related stress.

2. I spend a significant proportion of my workday coping with work stress.

3. Work stress distracts my attention away from my job tasks.

4. Mental energy I'd otherwise devote to my work is squandered on work stressors.

5. I delay starting on new projects at work because of stress.

6. I spend time talking to co-workers about stressful work situations.

This is a relatively new scale and although the pilot test shows good internal-consistency reliability and validity, it does not carry the weight of research of the SPS-6 and HPQ.

\section{Measures sensitive to depression}

Sanderson et al (2007) investigated measures sensitive to depression and anxiety. A study in ten call centres examined the association of presenteeism (presenteeism days, inefficiency days, Work Limitations Questionnaire, Stanford Presenteeism Scale) with Patient Health Questionnaire depression and anxiety syndromes. While at baseline, all presenteeism measures were sensitive to differences between those with and without depression/anxiety, only the Work Limitations Questionnaire consistently showed worse productivity as depression severity increased, and sensitivity to remission and onset of depression/anxiety over the six-month follow-up. There was some evidence of individual depressive symptoms having a differential association with different types of job demands. However the authors warn that the study findings may not generalise to other occupational settings with different job demands. 


\subsection{Choosing a measure}

Schultz et al (2009) summarise helpfully the key measurement instruments that have been developed to tap into presenteeism as a construct. They conclude that estimating costs attached to presenteeism is not prudent:

'The high level of variability in potential cost attributed to presenteeism does not give much confidence that any one estimate is accurate, at least according to this study. It may be safe to say that presenteeism is associated with some amount of costs and may even be a major contributor to the cost of certain conditions, but assigning a dollar value to that cost may not be prudent at this time.'

Monneuse (2013) recommends using a combination of quantitative and qualitative measures; statistical techniques providing an indication of the scale of the problem complemented by in depth qualitative data to ascertain motives and context.

\subsection{Summary of key findings}

Reporting presenteeism and productivity loss is highly subjective and relies on the measurement instrument and phrasing of questions. There is a wide variability on how employees have scored on different measures although many have proven validity.

Measures are likely to be more reliable as a within-company means of monitoring shifts in absenteeism and presenteeism trends (rather than between-company comparisons) and in providing data to evaluate the impact of workplace health interventions.

The choice of measure depends on whether the scale will be a stand-alone survey or incorporated into another instrument, for example, the staff survey.

The items can be general or related to specific health problems. For example, if stress is an important problem in the organisation, the Gilbreath and Frew scale might be appropriate. The SPS-6 can also be adapted for specific illnesses.

For a stand-alone study several scales could be combined looking at specific areas of organisational interest such as employee engagement, job satisfaction, work productivity or work limitations. This approach might be used in order to test a specific hypothesis. 


\section{Workplace interventions}

How then can organisations become more active in managing absenteeism and presenteeism together in order to promote a healthy and productive workforce?

Hemp (2004) suggests three courses of action for organisations:

- Awareness: organisations should raise awareness of the problem of presenteeism and the economic impact of health conditions on business and the economy.

- Identification: getting to know particular health issues affecting employees, in order to design better programmes to improve their health. These might range from ergonomic improvements for physical conditions to supporting healthy eating or workplace exercise.

Education: provide information and education for employees to ensure that illnesses are not going undiagnosed. This might include lifestyle, work life balance, opening up discussions on mental illness, etc. Ashby and Mahdon (2010) also advocate reviewing the provision of financial education to ensure the right support is reaching those who need it.

\subsection{The role of senior managers}

The Health Enhancement Research Organization's (HERO) research shows organisational support to be an important mediator in presenteeism (see Section 4.8). A key recommendation is that senior managers treat absenteeism and presenteeism holistically and strategically and give it high priority. This means considering what data will provide a full picture of health and productivity.

The Integrated Benefits Institute (IBI) in the US recommend three key 'big data' questions for CEOs:

What is the total health experience of the population of my employees?

Where in the organisation are results coming from and what needs our attention? 
How can I take action to improve my results?

Existing absence and staff survey data provide important context, enabling organisations to develop targeted interventions.

\subsection{The role of line managers}

Several studies have highlighted the impact of line managers/supervisors as role models, counsellors and support for employee wellbeing (see Sections 3.2.1 and 3.3; Section 4.8; Section 6.4). Supervisor support is shown to mitigate the negative impact of presenteeism.

Qualitative data from Baker-McClearn et al (2010), however, indicate that managers often feel under pressure themselves from HR and senior managers to control absence but are uncomfortable in carrying out certain tasks, such as return-to-work interviews. While HR departments have devolved more responsibility for absence management to managers there is often inadequate training in 'people management' and inconsistency in managers' skills. Employees described return-to-work interviews as a 'telling off' rather than a means of receiving support.

The Gilbreath and Karimi (2012) study highlighted in Section 4.6 showed that the supervisor behaviour with the highest negative correlation with job-stress-related presenteeism was 'helps employees keep work in perspective'.

\subsubsection{Recommended actions for managers}

Presenteeism is a complex problem for line managers, requiring some knowledge of (or at least interest in) a potentially wide range of illnesses as well as empathy, ability to broach sensitive subjects and judgement in how best to support employees while balancing the interests of the individual, the team and the organisation. Line managers may well not see this as their role.

Nevertheless, the important actions for line managers from the various research studies are summarised below:

- MIND concludes that 'it is vital that managers are equipped with the tools they need to be able to confidently and effectively support their staff, whether they are experiencing stress or other mental health problems as a result of work or other factors'. This means looking out for signs of stress and being prepared to listen. Less than a third felt they could talk to line managers about stress.

- The Centre for Mental Health suggests that training and awareness raising should be provided for both managers and employees so that they can have a better 
understanding of mental health in the workplace, including actions they can take themselves. This will also help to reduce the stigmatising of mental health conditions like depression, and will facilitate a more open approach to disclosing mental health conditions.

- The OECD also highlight the importance of good management to support workers with mental health issues and recommend that managers give adequate feedback, recognise work effort and talk to the employee.

- Ashby and Mahdon (2010) propose that line managers' capability to deal with workrelated stress, including the managerial and organisational causes of reduced psychological wellbeing and stress, should be prioritised. They should be able to 'notice the signals associated with employees experiencing high levels of stress, reduced psychological wellbeing and/or mental health problems'.

- Managers should understand how to apply absence policies effectively and the cultural messages they are intended to give so that it is clear that it is a wellbeing support mechanism rather than organisational policing.

- Munir et al (2008) recommend improving return-to-work competency skills (see Section 6.4 below).

- Managers should lead by example. Ramsey (2006) describes the managerial tendency to the 'Iron Man Mentality', where absence is seen as a sign of weakness rather than the 'indispensable man', who cannot be replaced. Supervisors and managers are particularly prone to this kind of behaviour. Ramsey argues that presenteeism should not be tolerated and advocates eight practical actions targeted at the acute category of infectious or contagious illness:

1. Educate: some have used flow charts to show the spread of infection through a workplace.

2. Modelling: supervisors should use their own sick leave when needed.

3. Send them home: people soon get the message.

4. The hand washing habit: showing people the correct technique and making it a workplace habit.

5. Cover-the-cough campaign: raising awareness of how germs spread and encouraging hygienic behaviours.

6. Disinfect the workplace: use anti-bacterial soaps and wipes and clean phones, keyboards, door handles. 
7. Encourage flu shots: consider sponsoring them.

8. Shut down.

Some workplaces such as call centres are particularly vulnerable to seasonal illnesses due to the open plan office and hot-desking.

\subsection{Work health promotion}

Work health promotions are often undertaken in the belief that they are inherently a good thing and must produce benefits. Unlike return to work programmes, they are preemptive in promoting healthier workplaces. Cancelliere et al's (2011) systematic review of literature ${ }^{2}$ on Workplace Health Promotion (WHP) and their effectiveness in improving presenteeism gives some idea of how little rigorous research has been undertaken in this field. They conclude, however, that while the presenteeism literature is young, there is preliminary evidence for a positive effect of some WHP programmes. Successful programmes identified focused on:

- Organisational leadership

- Health risk screening

- Individually tailored programmes

- Supportive workplace culture.

In particular there was preliminary evidence to support the use of one or more of the following:

- Involving employees' supervisors/managers in WHP programmes.

- Targeting organisational and/or environmental factors to influence behaviour.

- Screening workers prior to intervention using HRA (Health Risk Assessment) ${ }^{3}$ or other methods.

- Improving supervisor/manager knowledge regarding mental health in the workplace.

2 2,032 titles and abstracts screened in English only, reviewed 47 articles of which only 14 were accepted (4 strong and 10 moderate studies were included).

${ }^{3}$ Includes the assessment of personal health habits and risk factors, estimation of future risk of adverse health outcomes, and feedback in the form of education and counselling to alter risk factors. 
- Allowing physical exercise to occur during working hours and individually tailoring programmes.

- Grounding interventions in behaviour change models to help reinforce desirable lifestyle behaviours.

- Using participatory approaches with high employee involvement to develop interventions.

- Increasing the frequency and duration of rest breaks for workers required to stand for prolonged periods.

\subsection{Return to work programmes}

Return to work programmes provide the important link between absence and presence for employees who have been ill and can serve to reduce both absenteeism and presenteeism. Munir et al (2008) recommend:

- Individuals returning to work following long-term sick leave require ongoing adjustments and support.

- Line managers require better training on return-to-work management competency skills.

- An interactive occupational health psychology 'tool box' may help OH professionals and line managers to monitor the psychological wellbeing of those returning to work following long-term sick leave.

- There should be increased $\mathrm{OH}$ collaboration between line managers, HR and treating health practitioners.

- More research is required to evaluate the beneficial effects of stress management training for those returning to work.

\subsection{Workplace culture}

Ashby and Mahdon (2010) highlight the importance of how absence management policies are understood and applied by managers at all levels of the organisation and whether they are applied consistently so that employees understand how the sickness absence management systems and processes can benefit them.

They also suggest a review of how managers and their teams work together to help adjust work for employees and accommodate their health problems. 
Johns (2010) similarly suggests that co-workers and superiors be aware of the connection between a person's medical condition and their productivity so that accommodations are made, such as in job design or adjusted performance appraisals.

Other supportive behaviours suggested by the Work Foundation are financial support for employees such as workplace financial education offered at AXA PPP.

Watson Wyatt suggests linking this type of support to the employee value proposition in order to drive sustained healthy behaviours.

\subsection{Summary of key findings}

While senior managers are important in establishing an overall health strategy, a key focus for intervention is at the line manager/supervisor level. Their behaviour is influential in providing support, return-to-work interviews and work adjustments to facilitate the return, role modelling healthy behaviours and establishing a healthy team culture. Nevertheless qualitative research findings show that they often feel ill-equipped to manage return to work and lack understanding in how to deal with depression, stress and other psychological conditions.

Return to work programmes help to optimise performance for those transitioning from absenteeism to presenteeism. Collaboration between the employee, Occupational Health, HR and line managers is recommended in designing tailored solutions. 


\section{Conclusions}

While it remains tricky to assess the full impact of presenteeism on productivity in a formulaic way, there is sufficient evidence to suggest that it is a phenomenon with farreaching consequences. Several studies, such as the KPMG-Econtech study in Australia, conclude that there is a substantial opportunity for business managers to improve corporate performance by supporting and investing in measures that improve functioning for individuals with health conditions. Organisations often invest in wellbeing programmes as evidence of a 'caring culture' and as part of being an 'employer of choice', but there is little evidence outside the academic community that they are putting resources into a deeper understanding of presenteeism as a phenomenon.

An important exception is the study by Ashby and Mahdon (2010) for AXA PPP Healthcare who had a professional interest in the topic for their clients but also found considerable variation in spells of absence across their own 248 manager-led teams across the company: otherwise their attendance rates were typical, labour turnover low and engagement scores fairly high. The study revealed that over 40 per cent of employees perceived pressure from senior managers, line managers and colleagues to come to work when unwell. Combined with work-related stress, this was associated with lower levels of performance. Where permission was given, survey responses were matched with recorded absence data and individual performance scores based on line manager assessments. The study has enabled them to identify vulnerable groups and take action to raise awareness of the dangers of presenteeism both in their own organisation and with their clients.

Bespoke studies are therefore likely to be more important in the future as organisations tackle the important area of raising productivity. Research tends to show that context is highly relevant when assessing both the causes and impact of presenteeism.

From research in nine case study organisations Baker-McClearn et al (2010) recommend that organisations tailor their solutions for different people, teams and settings and use multiple ways of assessing productivity and efficiency, moving away from the tendency to use absence data. 
With the right data, tailored solutions to combat lost productivity from presenteeism in organisations are likely to become an area of competitive advantage.

Bespoke studies allow organisations to:

- Work with their own demographic, sickness and absence data, staff survey data or other HR metrics such as engagement scores to test out hypotheses.

- Target specific issues of strategic importance.

- Investigate and compare the characteristics of low/high presence teams.

- Raise awareness of the issue in the organisation by allocating resources to it and generating discussion.

- Target specific 'at risk' groups (these might relate to hierarchy, diversity or by role/profession) and identify focused and tailored interventions to minimise productivity loss.

- Identify cultural pressures that might lead to unnecessary presenteeism such as management style, values or policies that are driving behaviour.

- Enable ongoing tracking of trends of absence/presenteeism, such as the impact of presenteeism on long-term sickness rates.

\subsection{The challenges and possible solutions}

The challenges for a bespoke study range from measurement issues to engaging employees in supporting the aims.

\begin{tabular}{|l|l|}
\hline Challenges & Potential Solutions \\
\hline $\begin{array}{l}\text { Difficulties in measuring } \\
\text { presenteeism (Section 5.1) } \\
\text { It is easier to measure the occurrence } \\
\text { of presenteeism than its impact on } \\
\text { productivity, particularly in } \\
\text { knowledge-based roles as there are } \\
\text { limited valid measures of productivity. }\end{array}$ & $\begin{array}{l}\text { Choose a well-tested scale (several items with good psychometric } \\
\text { properties) such as the SPS-6. This could form part of a bespoke } \\
\text { survey incorporating other recognised measures such as } \\
\text { employee engagement or a work productivity measure. } \\
\text { Alternatively if embedded in the annual staff survey, it could } \\
\text { provide valuable internal benchmarking data which could be } \\
\text { correlated with other staff survey items and used to track activity } \\
\text { following the introduction of any new absence policies. }\end{array}$ \\
\hline $\begin{array}{l}\text { Measuring productivity and } \\
\text { understanding the multiple drivers } \\
\text { (independent variables) }\end{array}$ & $\begin{array}{l}\text { According to Mattke et al (2007), firm-level methods are based on } \\
\text { the premise that managers have a good sense of how their } \\
\text { company's productivity is affected by health-related problems and } \\
\text { the countermeasures used to deal with them. Using a combination } \\
\text { of quantitative and qualitative data would provide a clearer picture } \\
\text { of what presenteeism means across the organisation. Findings can } \\
\text { subsequently be explored through workshops to delve deeper into } \\
\text { the complexities of presenteeism. }\end{array}$ \\
\hline
\end{tabular}




\begin{tabular}{|l|l|}
\hline Challenges & Potential Solutions \\
\hline $\begin{array}{l}\text { Ensuring data is meaningful } \\
\text { Overcoming self-reporting bias }\end{array}$ & $\begin{array}{l}\text { Use multiple methods. Supplement quantitative data with } \\
\text { qualitative data gathering methods. If possible with permission, } \\
\text { correlate findings with absence data and performance scores. } \\
\text { Recognise that self-report data also has strengths in that the } \\
\text { person is best placed to assess how they are feeling when faced } \\
\text { with their work tasks. An objective diagnosis isn't always correct } \\
\text { and can't necessarily predict the severity of symptoms particularly } \\
\text { where physical and psychological symptoms are combined. When } \\
\text { diagnosing mental health, clinicians also have to rely largely on } \\
\text { subjective information from the affected person. }\end{array}$ \\
\hline Problems of confidentiality & $\begin{array}{l}\text { Complete transparency about the use of data. Trade Union or } \\
\text { Works Council support could be important, and employee buy-in. } \\
\text { The AXA/PPP study (Ashby and Mahdon, 2010) got employee } \\
\text { permission to match their survey responses to their line managers' } \\
\text { individual performance rating. }\end{array}$ \\
\hline Employee engagement & $\begin{array}{l}\text { A clear early statement of aims and reasons for undertaking the } \\
\text { study. Careful positioning of the project more squarely in the field } \\
\text { of employee wellbeing than is possible with absence, which might } \\
\text { be seen as a means of increasing corporate control. }\end{array}$ \\
\hline Employee ownership & $\begin{array}{l}\text { The involvement of employees through working groups across the } \\
\text { organisation in the design of a study increases ownership of the } \\
\text { process and outcomes. This might involve help in designing the } \\
\text { content but also in designing the process. }\end{array}$ \\
\hline
\end{tabular}

\subsection{Finally}

In spite of the challenges, the various strands of research covered in this report support further investigation of the phenomenon of presenteeism. This relatively new field reflects a growing interest in supporting wellbeing rather than simply controlling absence. It is a field of study that sits well with work and wellbeing programmes and employee engagement policies. For employees it offers the possibility of greater support when they might prefer to be with colleagues at work but reassurance that when they need to be absent they are not under undue scrutiny. For the wider economy it offers the possibility of greater productivity and a reduction in sickness benefits as organisations foster positive presenteeism alongside positive absenteeism. 


\section{References}

Allen H, Hubbard D, Sullivan S (2005), 'The high impact of pain on employee health and productivity: a case study', Health and Productivity Management, Vol. 4, No. 3

Arnold D (2013), The Intensive Margin of Sickness Presenteeism: Empirical Evidence from European Survey Data, paper presented to TEPP Conference "Research on Health and Labour" Le Mans, France, 26-27 September 2013

Aronsson G, Gustafsson K (2005), 'Sickness presenteeism: prevalence, attendancepressure factors, and an outline of a model for research', Journal of Occupational and Environmental Medicine, Vol. 47, No. 9

Aronsson G, Gustafsson K, Dallner M (2000), 'Sick but yet at work. An empirical study of sickness presenteeism', Journal of Epidemiology and Community Health, Vol. 54, pp. 502509

Ashby K, Mahdon M (2010) Why Do Employees Come to Work When Ill? An Investigation into Sickness Presence in the Workplace, The Work Foundation

Baker-McClearn D, Greasley K, Dale J, Griffith F (2010), 'Absence management and presenteeism: the pressures on employees to attend work and the impact of attendance on performance', Human Resource Management Journal, Vol. 20, No. 3

Bennet J (2012), 'Relationship Between Fatigue and Productivity: Industry Example from Rio Tinto West Angelas Operation', Rio Tinto [Online]. Available from: www.icmm.com/document/4380 [Accessed 9 September 2015]

Bergström G, Bodin L, Hagberg J, Aronsson G, Josephson M (2009), 'Sickness presenteeism today, sickness absenteeism tomorrow? A prospective study on sickness presenteeism and future sickness absenteeism', Journal of Occupational and Environmental Medicine, Vol. 51, pp. 629-638

Berry L L, Mirabito A M, Baun W B (2010), 'What's the hard return on employee wellness programs?', Harvard Business Review [Online]. Available from: 
http://hbr.org/2010/12/whats-the-hard-return-on-employee-wellness-programs/ [Accessed 13 January 2016]

Bierla I, Huver B, Richard S (2011), 'Presenteeism at work: the influence of managers', International Journal of Business and Management Studies, Vol. 3, No. 2

Bierla I, Huver B, Richard S (2013), 'New evidence on absenteeism and presenteeism', International Journal of Human Resource Management, Vol. 24, No. 7

Bockerman P, Laukkanen E (2010), 'What makes you work while you are sick? Evidence from a survey of workers', European Journal of Public Health, Vol. 20, pp. 43-46

Brun J-P, Biron C (2006), 'Absentéisme et présentéisme: entre la maladie, la paresse ouvrière et la responsabilité professionnelle', Communication présentée au 74e Congrès de l'ACFAS

Burton N W, Pransky G, Conti D J, Chen C, Edington D W (2004), 'The association of medical conditions and presenteeism', Journal of Occupational Environmental Medicine, Vol. 46: S38-S45

Cancelliere J, Cassidy D, Ammendolia C, Côté P (2011), 'Are workplace health promotion programs effective at improving presenteeism in workers? A systematic review and best evidence synthesis of the literature', BMC Public Health, Vol. 11

Caverley N, Barton Cunningham J, MacGregor J N (2007), 'Sickness presenteeism, sickness absenteeism, and health following restructuring in a public service organization', Journal of Management Studies, Vol. 44, No. 2

Center for Mental Health (2011), Managing Presenteeism: A Discussion Paper. Centre for Mental Health [Online]. Available from:

http://www.centreformentalhealth.org.uk/managing-presenteeism [Accessed 13 January 2016]

Chatterji M, Tilley C J (2002), 'Sickness, absenteeism and sick pay', Oxford Economic Papers, Vol. 54, pp. 669-687

Collins J J, Baase C M, Sharda C E, Ozminkowski R J, Nicholson S, Billotti G M, Turpin R S, Olson M, Berger ML (2005), 'The assessment of chronic health conditions on work performance, absence and total economic impact for employers', Journal of Occupational Environmental Medicine, Vol. 47, pp. 547-57

Lang S S (2004), 'Economists Coin New Word, 'Presenteeism,' To Describe Worker Slowdowns', Cornell University [Online]. Available from: 
http://www.news.cornell.edu/stories/2004/04/new-word-job-health-problempresenteeism [Accessed: 28 January 2016]

Czeisler C A, Fryer B (2006), 'A conversation with Charles A. Czeisler: sleep deficit: the performance killer', Harvard Business Review

Demerouti E, Le Blanc P, Bakker A B, Schaufeli W B, Hox J (2009), 'Present but sick: a three-wave study on job demands, presenteeism and burnout', Career Development International, Vol. 14, No. 1

Dew K, Keefe V, Small K (2005) 'Choosing to work when sick: workplace presenteeism', Social Science and Medicine, Vol. 60, pp. 2273-82

Dixon K (2005), 'Weighing the costs of presenteeism: recognise the signs and repair the damage of employee burnout', Chief Executive-New York, Vol. 209, pp. 22-23

Elstad JI, Vabo M (2008) 'Job stress, sickness absence and sickness presenteeism in Nordic elderly care' Scandinavian Journal of Public Health Vol. 36, No. 5

Epson (2013) ‘9.6 Million Work Days Lost Each Year to Winter Blues', Epson [Online]. Available from:

https:/www.epson.co.uk/gb/en/viewcon/corporatesite/press/index?gatewayto=/gb/en Lcontent/press/messages/message.php\%3Fid=3961\%26filtercat=archive [Accessed: 13 January 2016]

Eurofound (2012), 'Health and Wellbeing at Work: A Report Based on the Fifth European Working Conditions Survey', European Foundation for the Improvement of Living and Working Conditions [Online]. Available from:

http://www.eurofound.europa.eu/pubdocs/2013/02/en/1/EF1302EN.pdf [Accessed 13 January 2016]

Eurofound (2013) 'Impact of the Crisis on Working Conditions in Europe', European Foundation for the Improvement of Living and Working Conditions [Online]. Available from: https://hiva.kuleuven.be/resources/pdf/publicaties/R1534 tn1212025s.pdf [Accessed: 13 January 2016]

Gilbreath B, Karimi L (2012), 'Supervisor behaviour and employee presenteeism', International Journal of Leadership Studies, Vol. 7, No. 1

Goetzel R Z, Long S R, Ozminkowski R J, Hawkins K, Wang S, Lynch W (2004), 'Health, absence, disability, and presenteeism cost estimates of certain physical and mental health conditions affecting US employers', Journal of Occupational Environmental Medicine, Vol. 46, pp. 398-412 
Gosselin E, Lauzier M (2010), Le présentéisme: lorsque la présence n'est pas garante de la performance, Document de recherche Département de relations industrielles (2010-01) Université du Québec

Hansen C D, Andersen J D (2008), 'Going ill to work - what personal circumstances, attitudes and work-related factors are associated with sickness presenteeism?', Social Science and Medicine, Vol. 67, pp. 956-964

Hansson M, Bostrom C, Harms-Ringdahl K (2005), 'Sickness absence and sickness attendance: what people with neck or back pain think', Social Science and Medicine, Vol. 52, pp. 2183-95

Heigl C (2013), Recommendations from ENWHP's Ninth Initiative: Promoting Healthy Work for Employees with Chronic Illness - Public Health and Work, European Network for Workplace Health Promotion (ENWHP)

Hemp P (2004), 'Presenteeism: at work - but out of it', Harvard Business Review, Vol. 82, pp. $49-58$

HERO (2013), 'New Findings and Realistic Solutions to Employee Presenteeism: A white paper from the Health Enhancement Research Organization', Health Enhancement Research Organization [Online]. Available from: http://hero-health.org/researchstudies/ [Accessed: 13 January 2016]

Huver B, Richard S, Vaneecloo N, Delclite T, Bierla I (2012), 'Sick but at work. An econometric approach to presenteeism', 15th IZA European Summer School in Labor Economics, Buch am Ammersee, April 23-29, 2012

Johns G (2010), 'Presenteeism in the workplace: a review and research agenda', Journal of Organizational Behavior, Vol. 31, No. 4

KPMG Econtech (2011) Sick at Work, The Cost of Presenteeism to Your Business and the Economy and its update Economic Modelling of the Cost of Presenteeism in Australia: 2011 Update, KPMG Econtech

Kivimäki M, Head J, Ferrie J E, Hemingway H, Shipley M J, Vahtera J, Marmot M G (2005), 'Working while ill as a risk factor for serious coronary events: the Whitehall II study', American Journal of Public Health, Vol. 95, pp. 98-102

Klachefsky M (2012) Understanding Presenteeism, The Standard Insurance Company

Knies S, Candel M J, Boonen A, Evers S M, Ament A J, Severens J L (2012), 'Lost productivity in four European countries among patients with rheumatic disorders: are absenteeism and presenteeism transferable?' PharmacoEconomics, Vol. 30, No. 9 
Koopman C, Pelletier K R, Murray J F, Sharda C E, Berger M L, Turpin R S, Hackleman P, Gibson P, Holmes D M, Bendel T (2002), 'Stanford presenteeism scale: health status and employee productivity', Journal of Occupational Environmental Medicine, Vol. 44, No. 1

Layard R (2013), Mental Health: The New Frontier for Labour Economics, CEP Discussion Paper No 1213, Centre for Economic Performance

Léger D, Massuel M A, Metlaine A and the SISYPHE Study Group (2006), 'Professional correlates of insomnia', SLEEP, Vol. 29, No. 2

Leineweber C, Westerlund H, Hagberg J, Svedberg P, Alexanderson K (2012), 'Sickness presenteeism is more than an alternative to sickness absence: results from the population-based SLOSH study', International Archives of Occupational and Environmental Health, Vol. 85, No. 8

Levin-Epstein J (2005) Presenteeism and paid sick days, Center for Law and Social Policy

Loeppke R, Hymel P A, Lofland J H, Pizzi L T, Konicki D L, Anstadt G W, Baase C, Fortuna J, Scharf T (2003), 'Health-related workplace productivity measurement: general and migraine specific recommendations from the ACOEM expert panel', Journal of Occupational and Environmental Medicine 2003, Vol. 45, No. 4

Lu, L, Cooper, C L, and Lin, H (2013), 'A cross-cultural examination of presenteeism and supervisory support', Career Development International, Vol. 18, No. 5

Mattke S, Balakrishnan A, Bergamo G, Sydney J (2007), 'Review of methods to measure health-related productivity loss', The American Journal of Managed Care, Vol. 13, No. 4

McKevitt C, Morgan M, Dundas R, Holland W W (1997), 'Sickness absence and 'working through' illness: a comparison of two professional groups', Journal of Public Health Medicine, Vol. 19, pp. 295-300

Medibank Private, Econtech (2008), 'Economic Impact of Workplace Stress in Australia', Medibank Private, Econtech [Online]. Available from: www.medibank.co.m.au/client/downloads/pdfs/the-cost-of-workplace-stress.pdf [Accessed: 13 January 2016].

Monneuse D (2009), L'Absenteisme au Travail: De l'Analyse à l'Action, Afnor Monneuse D (2013), Le Surprésentéisme: Travailler Malgré la Maladie, De Boeck

Mudrack P E (2006), 'Understanding workaholism: the case of behavioral tendencies', in Burke R (ed), Work Hours and Work Addiction Vol. 6, Emerald Insight 
Munir F, Yarker J, Haslam C (2008), 'Sickness absence management: encouraging attendance or 'risk-taking' presenteeism in employees with chronic illness?', Disability and Rehabilitation, Vol. 30, No. 19

Munir F, Mackay C, Yarker J, Haslam C, Kazi A, Cooper L (2009), 'Back, but not better: ongoing mental health hampers return to work outcomes', Occupational Health at Work, Vol. 5, No.5

Office for National Statistics available at: https://www.gov.uk/government/statistics

Organisation for Economic Co-operation and Development (OECD) (2010), Disability and Work. Breaking the Barriers. A Synthesis of Findings Across OECD Countries, OECD Publications

Organisation for Economic Co-operation and Development (OECD) (2012), Sick on the Job? Myths and Realities About Mental Health and Work, OECD Publications, Paris

Parry T (2007), From Presenteeism to Productivity, Integrated Benefits Institute

Parry T, Jinnett K (2006), The Business Value of Health: Linking CFOs to Health and Productivity, Integrated Benefits Institute

Parry T, Molmen W (2002), On the Brink of Change: How CFOs View Investments in Health and Productivity, Integrated Benefits Institute

Ramsey R (2006), ‘Presenteeism a new problem in the workplace', Supervision, Vol. 67, No. 8

Rosvold E O, Bjertness E (2001), 'Physicians who do not take sick leave: hazardous heroes?' Scandinavian Journal of Public Health, Vol. 29, pp. 71-75

Sanderson K, Tilse E, Nicholson J, Oldenburg B, Graves N (2007), ‘Which presenteeism measures are more sensitive to depression and anxiety?', Journal of Affective Disorders, Vol. 101, No. 1

Schaufeli W, Bakker A, van der Heijden F, Prins J (2009), 'Workaholism among medical residents: it is the combination of working excessively and compulsively that counts', International Journal of Stress Management, Vol. 16, pp. 249-272

Schultz A B, Chen C, Edington D W (2009), 'The cost and impact of health conditions on presenteeism to employers: a review of the literature', Pharmacoeconomics, Vol. 27, No. 5 
Schwartz B S, Stewart W F, Lipton R B (1997), 'Lost work days and decreased work effectiveness associated with headache in the workplace', Journal of Occupational Environmental Medicine, Vol. 39, pp. 320-37

Søgaard R, Sørensen J, Linde L, Hetland M L (2010), 'The significance of presenteeism for the value of lost production: the case of rheumatoid arthritis', ClinicoEconomics and Outcomes Research, Vol. 2, pp. 105-112

Steers R M, Rhodes SR (1978) 'Major influences on employee attendance: A process model', Journal of Applied Psychology, Vol 63, No. 4

Stewart W F, Ricci J A, Chee E, Morganstein D (2003), 'Lost productive work time costs from health conditions in the United States: results from the American Productivity Audit', Journal of Occupational and Environmental Medicine, Vol. 45, pp. 1234-1246

Swanson L, Arnedt J T, Rosekind M R, Belenky G, Balkin T J, Drake C (2011), 'Sleep disorders and work performance: findings from the 2008 National Sleep Foundation Sleep in America poll', Journal of Sleep Research, Vol. 20, pp. 487-494

Taylor P, Baldry C, Bain B, Ellis V (2003) 'A unique working environment: health, sickness and absence management in UK call centres', Work, Employment and Society, Vol. 17, No. 3

Vézina M, Cloutier E, Stock S, Lippel K, Fortin E, Delisle A, St-Vincent M, Funes A, Duguay P, Vézina S, Prud'homme P (2011), Quebec Survey on Working and Employment Conditions and Occupational Health and Safety, Institut de recherche Robert-Sauvé en santé et sécurité du travail (IRSST)

VingÅrd E, Alexanderson K, Norlund A (2004), 'Sickness presence', Scandinavian Journal of Public Health, Vol. 32, p. 216

Virtanen M, Kivimäki M, Elovainio J, Vahtera J, Ferrie J E (2003), ‘From insecure to secure employment: changes in work, health, health related behaviours, and sickness absence', Occupational and Environmental Medicine, Vol. 60, pp. 948-953 


\section{Appendix 1: Drivers of presenteeism}




\section{Organisational factors}

Cultural factors (professional, team, organisational)

\begin{tabular}{|c|c|c|}
\hline $\begin{array}{l}\text { The needs of } \\
\text { others }\end{array}$ & $\begin{array}{l}\text { Presenteeism is prevalent in jobs where attendance has a great influence on other } \\
\text { people and on their primary needs such as the education sector, and care and welfare. } \\
\text { The reverse is true for the service staff, (hospital workers but whose relationship with } \\
\text { patients is more distant than nurses and direct care givers). }\end{array}$ & $\begin{array}{l}\text { Aronsson et al (2000) The first major study of } \\
\text { sickness presenteeism in Sweden in 1997. 3,801 } \\
\text { people interviewed by telephone. } \\
\text { Huver et al (2012) A longitudinal statistical } \\
\text { analysis of a French hospital of } 3,600 \\
\text { employees. }\end{array}$ \\
\hline $\begin{array}{l}\text { Concerns for } \\
\text { colleagues }\end{array}$ & $\begin{array}{l}\text { Where replacement is impossible, employees want to spare their colleagues additional } \\
\text { workload. }\end{array}$ & $\begin{array}{l}\text { Caverley et al (2007) Survey ( } 237 \text { responses) in } \\
\text { a Canadian public service organisation involved } \\
\text { in a large scale downsizing initiative. }\end{array}$ \\
\hline $\begin{array}{l}\text { Manager } \\
\text { behaviour }\end{array}$ & $\begin{array}{l}\text { The manager's behaviour has a significant influence on the presenteeism of } \\
\text { subordinates. If a manager's probability of presenteeism increases from } 30 \text { per cent to } \\
80 \text { per cent, an average team member's own probability moves in the same direction } \\
\text { (from } 25 \text { per cent to } 36 \text { per cent). } \\
\text { Team managers feel responsible for their subordinates and want to ensure that the } \\
\text { activities run smoothly. Presenteeism more often occurs for managers and those with a } \\
\text { higher level of responsibility. } \\
\text { Widespread 'presenteeism' occurs when managers and supervisors fail to take days off } \\
\text { when sick themselves. }\end{array}$ & $\begin{array}{l}\text { Bierla et al (2011) Presenteeism measured } \\
\text { statistically (a zero-inflated negative binomial } \\
\text { model) from absence data taken from the social } \\
\text { audit in } 2008 \text { of a French regional bank. } \\
\text { Huver et al (2012) Op. Cit. } \\
\text { Caverley et al (2007) Op. Cit. } \\
\text { Ramsey (2006) US article }\end{array}$ \\
\hline $\begin{array}{l}\text { Supervisor } \\
\text { behaviour }\end{array}$ & $\begin{array}{l}\text { Negative supervisor behaviours were found to have the strongest associations with } \\
\text { employee job-stress-related presenteeism (defined as a form of psychological strain } \\
\text { whose antecedent is job stress). }\end{array}$ & $\begin{array}{l}\text { Gilbreath and Karimi (2012) A survey in two } \\
\text { Australian hospitals with } 149 \text { responses. }\end{array}$ \\
\hline $\begin{array}{l}\text { Organisational } \\
\text { culture }\end{array}$ & $\begin{array}{l}\text { A 'culture of presenteeism' highlights the social nature of the phenomenon. He cites a } \\
\text { study by Dew et al (2005) in: a public hospital ('battleground' culture with distant } \\
\text { management but where professional and ethnic identity and institutional loyalty foster } \\
\text { presenteeism); a private hospital ('sanctuary' culture where strong teamwork and co- } \\
\text { workers foster presenteeism); and a manufacturing firm ('ghetto' culture where poor } \\
\text { working conditions and insecurity prompted presenteeism). }\end{array}$ & Johns (2010) from a review of research \\
\hline
\end{tabular}




\begin{tabular}{|l|l|l|}
\hline Work ethic & $\begin{array}{l}\text { 'Older employees and managers taught younger ones that they should discuss } \\
\text { problems, get them sorted out and turn up for work and that it was not the 'done thing' to } \\
\text { go off sick. This was the 'work ethic' passed down from worker to worker and impacted } \\
\text { on the decision to be absent. The perception that taking time off sick as a sign of under- } \\
\text { performance was not always explicitly stated, but was often subtly evident in informal } \\
\text { conversations, particularly in private sector organisations.' }\end{array}$ & $\begin{array}{l}\text { Baker-McClearn et al (2010) Qualitative data } \\
\text { from a power company case study. }\end{array}$ \\
\hline $\begin{array}{l}\text { Organisational } \\
\text { commitment }\end{array}$ & $\begin{array}{l}\text { Perfect work attendance, whatever the circumstances, is sometimes perceived by } \\
\text { employees as organisational commitment and loyalty. }\end{array}$ & $\begin{array}{l}\text { Hansen and Andersen (2008) A postal survey of } \\
\text { a random sample of the Danish core workforce } \\
\text { aged 19 to 64 years. 12,935 responses. }\end{array}$ \\
\hline
\end{tabular}

\section{Organisational policies and economic climate}

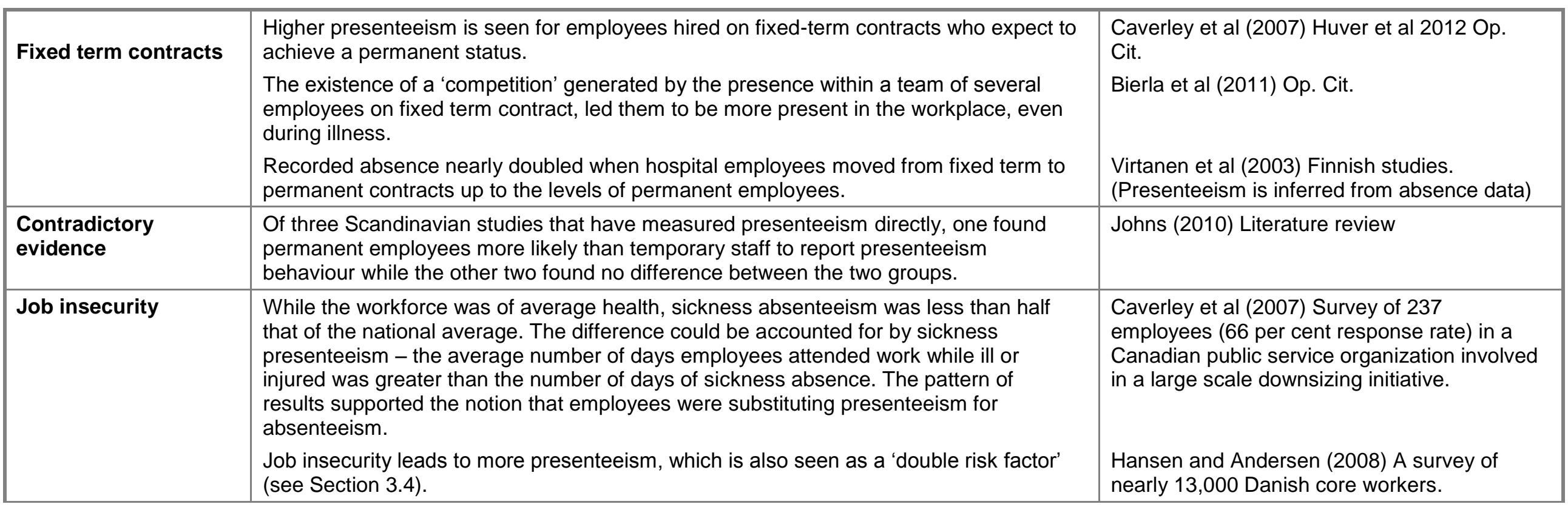




\begin{tabular}{|c|c|c|}
\hline $\begin{array}{l}\text { Global financial } \\
\text { crisis (GFC) }\end{array}$ & $\begin{array}{l}\text { Incidences of sickness absence in the UK dropped to a record low point during the } \\
\text { GFC, then returned to pre-GFC levels once the worst of the crisis was over. (Late } 2008 \\
-2.5 \text { per cent absenteeism, March quarter } 2009-2.1 \text { per cent absenteeism, } \\
\text { December quarter } 2010-2.5 \text { per cent absenteeism). There is, however, no research to } \\
\text { see how far this has translated into presenteeism. }\end{array}$ & UK Office of National Statistics \\
\hline $\begin{array}{l}\text { Policies designed to } \\
\text { reduce absence }\end{array}$ & $\begin{array}{l}\text { Policies implemented to reduce absence, such as a reduction in sick pay, were more } \\
\text { likely to increase presenteeism, which in turn could lead to more illness and lower } \\
\text { productivity. } \\
\text { Many interviewees perceived that their organisation's sickness absence policies and } \\
\text { procedures compelled attendance at work, especially where sick pay was withdrawn, or } \\
\text { there was a threat of disciplinary action or dismissal. In one case it was described as } \\
\text { 'bullying'. One public sector senior manager suggested that despite a reduction of } 1 \text { per } \\
\text { cent in absence rates 'on paper' brought about by rigidly adhering to policies, there } \\
\text { were problems with employees attending work sick, suffering stress and anxiety over } \\
\text { their absence, not wanting to hit the trigger point and subsequently becoming more } \\
\text { unwell. }\end{array}$ & $\begin{array}{l}\text { Chatterii and Tilley (2002) A mathematical } \\
\text { modelling study } \\
\text { Baker-McClearn et al (2010) } 123 \text { interviews in } \\
\text { nine UK case studies }\end{array}$ \\
\hline Sickness benefit & $\begin{array}{l}\text { Changes in the amount of sickness benefit and how it is paid can have a significant } \\
\text { impact on an employee's decision to stay at home (absenteeism) or come to work ill } \\
\text { (presenteeism). During the global financial crisis, several countries reduced benefits } \\
\text { which is seen as a key factor driving the declining absenteeism (and therefore potential } \\
\text { rise in presenteeism) in the various countries. } \\
\text { Employees who have no sick pay have a higher rate of presenteeism. }\end{array}$ & $\begin{array}{l}\text { The European Foundation for the } \\
\text { Improvement of Living and Working } \\
\text { Conditions (2013) } \\
\text { Bierla et al (2011) Op. Cit. }\end{array}$ \\
\hline $\begin{array}{l}\text { Bonus/incentives for } \\
\text { attendance }\end{array}$ & $\begin{array}{l}\text { Interviewees had mixed opinions; some felt that staff that had } 100 \text { per cent attendance } \\
\text { should be rewarded but many felt that the pursuit of incentives could make employees } \\
\text { feel unduly pressured to attend work. }\end{array}$ & Baker-McClearn et al (2010) Op. Cit. \\
\hline
\end{tabular}




\begin{tabular}{|c|c|c|}
\hline $\begin{array}{l}\text { Working time } \\
\text { arrangements }\end{array}$ & $\begin{array}{l}\text { Presenteeism is more sensitive to working time arrangements than absenteeism. The } \\
\text { following factors increase presenteeism: } \\
\text { Permanent full-time work } \\
\text { Mismatch between desired and actual working hours } \\
\text { Shift or period work } \\
\text { Overlong working weeks } \\
\text { Regular overtime decreases sickness absenteeism, but increases sickness } \\
\text { presenteeism } \\
\text { The adoption of three days' paid sickness absence without a certificate and the easing } \\
\text { of efficiency demands decrease sickness presenteeism. }\end{array}$ & $\begin{array}{l}\text { EU Labour Force Survey (2008) } \\
\text { Bockerman and Laukkanen (2010) A survey } \\
\text { of } 725 \text { Finnish union members controlling for } \\
\text { worker characteristics. }\end{array}$ \\
\hline
\end{tabular}

\section{Job strain and work pressures}

\begin{tabular}{|l|l|l|}
\hline Job demands & $\begin{array}{l}\text { Job demands caused more presenteeism, while depersonalisation was } \\
\text { an outcome of presenteeism over time. Exhaustion and presenteeism } \\
\text { were found to be reciprocal. }\end{array}$ & $\begin{array}{l}\text { Demerouti et al (2009) A longitudinal survey of 258 staff nurses at } \\
\text { three points over 18 months in the Netherlands. }\end{array}$ \\
\hline $\begin{array}{l}\text { Time pressures } \\
\text { Conflicting } \\
\text { demands } \\
\text { Work pressure }\end{array}$ & $\begin{array}{l}\text { Job demands in general (but also specific demands like time pressure, } \\
\text { conflicting demands (Aronsson and Gustafsson, 2005) and work } \\
\text { pressure (European Foundation for the Improvement of Living and } \\
\text { Working Conditions, 2013) are found to be positively related to } \\
\text { presenteeism. }\end{array}$ & $\begin{array}{l}\text { Kivimäki et al (2005) A study of 5,071 male British civil servants } \\
\text { without previous myocardial infarction - baseline health screening } \\
\text { was carried out. }\end{array}$ \\
\hline Pressure periods & $\begin{array}{l}\text { Employees were required to work large amounts of overtime to conduct } \\
\text { maintenance for which they earned extra money. Attendance was } \\
\text { expected and every employee had a designated role. At these times } \\
\text { there was very little absence but following such periods, absence often } \\
\text { increased. It seemed that presenteeism increased during the time of } \\
\text { high pressure, when organisational expectations are much higher, } \\
\text { whereas during less pressured times, presenteeism reduces and } \\
\text { absenteeism may increase. }\end{array}$ & $\begin{array}{l}\text { Baker-McClearn et al (2010) Case study data from two power } \\
\text { companies }\end{array}$ \\
\hline $\begin{array}{l}\text { Pressure from } \\
\text { colleagues and } \\
\text { managers }\end{array}$ & $\begin{array}{l}\text { 40 per cent of employees surveyed perceived pressure from senior } \\
\text { managers, line managers and colleagues to come to work when } \\
\text { unwell. }\end{array}$ & Ashby and Mahdon (2010) Survey of 510 AXA PPP employees \\
\hline
\end{tabular}




\begin{tabular}{|l|l|l|}
\hline $\begin{array}{l}\text { Other specific } \\
\text { factors }\end{array}$ & $\begin{array}{l}\text { Having no back-ups in the department } \\
\text { Heavy workload } \\
\text { Deadlines to meet } \\
\text { Work commitments (meetings) } \\
\text { Self-perception of not feeling too bad to come to work. }\end{array}$ & Caverley et al (2007) Op. Cit. \\
\hline $\begin{array}{l}\text { Other } \\
\text { unfavourable } \\
\text { working } \\
\text { conditions }\end{array}$ & $\begin{array}{l}\text { Positive association with presenteeism is observed with: } \\
\text { Exposure to work intensity } \\
\text { Verbal abuse or discrimination } \\
\text { Handling chemicals } \\
\text { Awkward postures } \\
\text { Shift work. }\end{array}$ & $\begin{array}{l}\text { Eurofound (2012) Based on fifth European Working Conditions } \\
\text { Survey }\end{array}$ \\
\hline $\begin{array}{l}\text { Workplace } \\
\text { stress }\end{array}$ & $\begin{array}{l}\text { Employees with lower levels of perceived workplace pressure, lower } \\
\text { work-related stress and fewer personal financial difficulties reported } \\
\text { fewer days of sickness presence compared to those with higher levels } \\
\text { of workplace pressure, work-related stress and greater financial } \\
\text { difficulties. As well as reporting a higher number of days' sickness } \\
\text { presence, employees who perceived pressure from managers and } \\
\text { colleagues to work when unwell were also more likely to report that } \\
\text { their performance was adversely affected by working when unwell. }\end{array}$ & $\begin{array}{l}\text { Ashby and Mahdon (2010) Qualitative interviews with three teams } \\
\text { of employees (25 interviews in total) where the teams had differing } \\
\text { levels of sickness absence. Followed by an online survey of 510 } \\
\text { AXA PPP employees. Where possible employees' survey } \\
\text { responses were matched with recorded absence data and individual } \\
\text { performance scores based on line manager assessments. }\end{array}$ \\
\hline $\begin{array}{l}\text { Supervisor } \\
\text { support and job } \\
\text { satisfaction }\end{array}$ & $\begin{array}{l}\text { Work factors } \text { job security, supervisor support and job satisfaction } \\
\text { were significantly correlated with presenteeism. }\end{array}$ & Caverley et al (2007) Op. Cit. \\
\hline
\end{tabular}




\section{Personal factors}

\begin{tabular}{|l|l|l|}
\hline Companionship & $\begin{array}{l}\text { Work is generally considered 'good' for } \\
\text { mental health. Being with colleagues is } \\
\text { better than being alone with worries or } \\
\text { depression. }\end{array}$ & $\begin{array}{l}\text { Vézina et al (2011) Quebec telephone } \\
\text { survey (35 minutes) of over 5,000 } \\
\text { representative workers }\end{array}$ \\
\hline $\begin{array}{l}\text { Home } \\
\text { circumstance }\end{array}$ & $\begin{array}{l}\text { Conditions at home are not always } \\
\text { conducive to rest. }\end{array}$ & Hansen and Andersen (2008) \\
\hline $\begin{array}{l}\text { Financial } \\
\text { pressure }\end{array}$ & $\begin{array}{l}\text { Being concerned about commission } \\
\text { and pay. } \\
\text { People with financial problems, ie, } \\
\text { facing private financial demands for } \\
\text { presence at work, showed an elevated } \\
\text { risk of sickness presenteeism. }\end{array}$ & $\begin{array}{l}\text { Ashby and Mahdon (2010) Op. Cit. } \\
\text { Aronsson and Gustafsson (2005) Random } \\
\text { sample of 3,136 respondents to a } \\
\text { questionnaire administered in conjunction } \\
\text { with Statistics Sweden's labor market } \\
\text { survey. }\end{array}$ \\
\hline Lifestyle & $\begin{array}{l}\text { Sickness presenteeism may be part of } \\
\text { a lifestyle in which symptoms of ill } \\
\text { health are ignored and medical care } \\
\text { not sought. }\end{array}$ & Kivimäki et al (2005) Op. Cit. \\
\hline
\end{tabular}




\section{Appendix 2: Vulnerable groups}

\begin{tabular}{|c|c|c|}
\hline Groups at risk & Findings & Studies \\
\hline Managers & $\begin{array}{l}\text { Managers felt that they had to be brave and set } \\
\text { a good example, and that their job could not be } \\
\text { done by anyone else. }\end{array}$ & Ramsey (2006) US article \\
\hline $\begin{array}{l}\text { People with } \\
\text { high sickness } \\
\text { absence }\end{array}$ & $\begin{array}{l}\text { Being absent due to illness for between one and } \\
\text { seven days in a year doubles the probability of } \\
\text { having more than } 8 \text { days of presenteeism during } \\
\text { the same period. }\end{array}$ & $\begin{array}{l}\text { Leineweber et al }(2012) \text { A } \\
\text { questionnaire from } 8,304 \text { working } \\
\text { women and men, from the Swedish } \\
\text { Longitudinal Occupational Survey of } \\
\text { Health }\end{array}$ \\
\hline $\begin{array}{l}\text { People with } \\
\text { financial } \\
\text { problems }\end{array}$ & $\begin{array}{l}\text { Employees who were finding it difficult to make } \\
\text { ends meet, who were unable to save and who } \\
\text { were worried a great deal about debt had a } \\
\text { significantly higher number of sickness presence } \\
\text { days than those without these problems. }\end{array}$ & Ashby and Mahdon (2010) Op. Cit. \\
\hline Workaholics & $\begin{array}{l}\text { Workaholism (constituted by the combination of } \\
\text { working excessively (WE) and working } \\
\text { compulsively (WC) - internally motivated to } \\
\text { work to an excessive extent. In addition to high } \\
\text { levels of presenteeism, they displayed the } \\
\text { highest burnout and lowest happiness levels } \\
\text { relative to other groups. They also experienced } \\
\text { the highest job demands, the poorest job } \\
\text { resources, the lowest levels of recovery and } \\
\text { performance. }\end{array}$ & $\begin{array}{l}\text { Schaufeli et al (2009) } 2,115 \\
\text { respondents - Dutch medical } \\
\text { residents in the } 2005 \text { national } \\
\text { register of the Royal Dutch Medical } \\
\text { Association. The majority were } \\
\text { women ( } 60.7 \text { per cent), and the } \\
\text { mean age of the sample is } 31.5 \\
\text { years (SD_3.5). Almost } 77 \text { per } \\
\text { cent were married or living with a } \\
\text { partner, } 32 \text { per cent of the } \\
\text { respondents have one or more } \\
\text { children. Presenteeism was } \\
\text { measured with a single item 'How } \\
\text { often did you go to work in the } \\
\text { previous year despite feeling sick?' }\end{array}$ \\
\hline Insomniacs & $\begin{array}{l}\text { Insomniacs missed work twice as often as good } \\
\text { sleepers. The difference between insomniacs } \\
\text { and good sleepers in terms of absenteeism was } \\
\text { particularly high for blue-collar workers and men. } \\
\text { Insomniacs had also a higher accident rate while } \\
\text { driving and a three-fold greater risk of having two } \\
\text { or three serious road accidents. They also } \\
\text { reported poor self-esteem at work, less job } \\
\text { satisfaction, and less efficiency at work, } \\
\text { compared with good sleepers. }\end{array}$ & $\begin{array}{l}\text { Léger et al (2006) French study of } \\
369 \text { matched pairs from } 738 \\
\text { questionnaire respondents }\end{array}$ \\
\hline
\end{tabular}




\begin{tabular}{|c|c|c|}
\hline Groups at risk & Findings & Studies \\
\hline $\begin{array}{l}\text { High-skilled, } \\
\text { white collar }\end{array}$ & $\begin{array}{l}\text { Prevalence of presenteeism was higher among } \\
\text { high-skilled white-collar workers (around } 50 \text { per } \\
\text { cent), compared to the other occupational } \\
\text { classes ( } 35 \text { per cent- } 38 \text { per cent), a pattern that } \\
\text { was observed also for mean days of } \\
\text { presenteeism. }\end{array}$ & $\begin{array}{l}\text { Eurofound (2012) Based on fifth } \\
\text { European Working Conditions } \\
\text { Survey, } 2010\end{array}$ \\
\hline $\begin{array}{l}\text { Qualification } \\
\text { level }\end{array}$ & $\begin{array}{l}\text { Presenteeism increases with qualification level: } \\
57.1 \text { per cent of the qualified employees } \\
\text { reported presenteeism, versus } 46.2 \text { per cent with } \\
\text { lower qualification levels. } \\
\text { High-skilled clerical workers displayed a } 20 \text { per } \\
\text { cent higher risk of sickness presenteeism } \\
\text { compared to subjects in other occupational } \\
\text { classes; this finding appears to be in contrast } \\
\text { with the results of other studies, where no } \\
\text { difference or a higher risk of sickness } \\
\text { presenteeism was found among workers in lower } \\
\text { occupational classes or with lower educational } \\
\text { level (Hansen and Andersen, 2008; Aronsson et } \\
\text { al, 2000). }\end{array}$ & $\begin{array}{l}\text { (European Working Conditions } \\
\text { Survey, 2010) }\end{array}$ \\
\hline Men & $\begin{array}{l}\text { In a hospital context, men seem to be more at } \\
\text { risk than women (Demerouti et al 2009). A } \\
\text { possible explanation is that women put more } \\
\text { effort into family life and childcare but the link } \\
\text { between presenteeism and family life is not } \\
\text { demonstrated. } \\
\text { However in the French part of the European } \\
\text { Working Conditions Survey (2010), there is no } \\
\text { significant difference between men and women. } \\
\text { Gender was not significantly associated with } \\
\text { presenteeism in two different studies in Sweden } \\
\text { and the Netherlands. (Schultz et al 2009) }\end{array}$ & Bierla et al (2011) \\
\hline Mixed teams & $\begin{array}{l}\text { Gender changes the probability of presenteeism: } \\
\text { other things being equal, it is lower for women. } \\
\text { When the team is mostly composed of men, } \\
\text { (individual) presenteeism is more important. }\end{array}$ & \\
\hline $\begin{array}{l}\text { Availability of } \\
\text { replacements }\end{array}$ & $\begin{array}{l}\text { In Finland the prevalence of women's sickness } \\
\text { presenteeism decreases by } 18 \text { per cent if } \\
\text { replacements are available but replaceability } \\
\text { does not affect men's presenteeism. Possibly } \\
\text { they are not as willing to leave their tasks to } \\
\text { others. The match between desired and actual } \\
\text { hours decreases the prevalence of sickness } \\
\text { presenteeism for women by } 11 \text { per cent while for } \\
\text { men the point estimate is } 7 \text { per cent though is } \\
\text { not statistically significant. Regular overtime } \\
\text { increases men's presenteeism by } 13 \text { per cent } \\
\text { but not women's. The three days' rule decreases } \\
\text { men's presenteeism by } 9 \text { per cent. Women's } \\
\text { presenteeism is } 16 \text { per cent higher at the } \\
\text { workplaces in which efficiency rules out } \\
\text { everything else. }\end{array}$ & Bockerman and Laukkanen (2010) \\
\hline
\end{tabular}




\begin{tabular}{|c|c|c|}
\hline Groups at risk & Findings & Studies \\
\hline $\begin{array}{l}\text { People with } \\
\text { unhealthy } \\
\text { lifestyle choices }\end{array}$ & $\begin{array}{l}\text { Smokers were } 28 \text { per cent more likely to have } \\
\text { high presenteeism than non-smokers. } \\
\text { Employees with an unhealthy diet were } 66 \text { per } \\
\text { cent more likely to have high presenteeism than } \\
\text { those who regularly ate whole grains, fruits, and } \\
\text { vegetables. } \\
\text { Employees who didn't exercise very much were } \\
50 \text { per cent more likely to have high } \\
\text { presenteeism than employees who were regular } \\
\text { exercisers. } \\
\text { Excess body weight, elevated blood pressure, } \\
\text { and high cholesterol increased the odds of } \\
\text { having high presenteeism. Those who reported it } \\
\text { was difficult to exercise during the day were } 96 \\
\text { per cent more likely to have high presenteeism. }\end{array}$ & $\begin{array}{l}\text { HERO (2013) Data from three } \\
\text { companies (insurance, health care } \\
\text { and customer service call centre) } \\
\text { involving } 20,000 \text { employees using } \\
\text { the Gallup-Healthways Wellbeing } \\
\text { Index }\end{array}$ \\
\hline \multirow[t]{2}{*}{ Older workers } & $\begin{array}{l}\text { The picture for older workers is not entirely clear. } \\
\text { Some of the conditions such as depression, } \\
\text { migraine and allergies which are associated with } \\
\text { presenteeism decrease with age. Others such as } \\
\text { hypertension, heart disease and back pain } \\
\text { increase and others remain flat. The report } \\
\text { concludes, 'The impact of Australia's ageing } \\
\text { population on productivity losses from } \\
\text { presenteeism increases over time but is muted'. }\end{array}$ & Medibank (2011) \\
\hline & $\begin{array}{l}\text { Found no explanatory value with regard to age } \\
\text { or gender for presenteeism. }\end{array}$ & $\begin{array}{l}\text { Aronsson and Gustafsson (2005) } \\
\text { Op. Cit. }\end{array}$ \\
\hline \multirow[t]{2}{*}{$\begin{array}{l}\text { Childless } \\
\text { employees }\end{array}$} & $\begin{array}{l}\text { Employees who had recently married or those } \\
\text { with one (young) child were less exposed to } \\
\text { presenteeism. Childless employees were more } \\
\text { likely to come to work being sick. }\end{array}$ & Huver et al 2012 \\
\hline & $\begin{array}{l}\text { It is seen as more 'socially legitimate' to be } \\
\text { absent with one child but this does not continue } \\
\text { with two children. }\end{array}$ & Bierla et al 2011 \\
\hline $\begin{array}{l}\text { Poor } \\
\text { psychological } \\
\text { wellbeing }\end{array}$ & $\begin{array}{l}\text { Sickness presence is significantly associated } \\
\text { with self-rated anxiety and psychological } \\
\text { wellbeing. Employees with a greater number of } \\
\text { days of sickness presence reported higher levels } \\
\text { of anxiety and lower levels of psychological } \\
\text { wellbeing whilst those with fewer days of } \\
\text { sickness presence reported the converse. }\end{array}$ & Ashby and Mahdon (2010) \\
\hline
\end{tabular}




\begin{tabular}{|c|c|c|}
\hline Groups at risk & Findings & Studies \\
\hline \multirow[t]{2}{*}{$\begin{array}{l}\text { Health risk } \\
\text { factors }\end{array}$} & $\begin{array}{l}\text { The presence of risk factors, pain and chronic } \\
\text { disease, especially chronic depression, } \\
\text { dramatically increase the odds of having high } \\
\text { presenteeism: } \\
\text { Knee/leg pain by } 72 \text { per cent } \\
\text { Neck/back pain by } 79 \text { per cent } \\
\text { Asthma by } 39 \text { per cent } \\
\text { Heart attack by } 34 \text { per cent } \\
\text { Depression by } 131 \text { per cent } \\
\text { Diabetes by } 19 \text { per cent } \\
\text { High cholesterol by } 16 \text { per cent } \\
\text { High blood pressure by } 23 \text { per cent } \\
\text { Obesity by } 42 \text { per cent } \\
\text { Overweight by } 17 \text { per cent }\end{array}$ & $\begin{array}{l}20,000 \text { employees in diverse } \\
\text { industries including insurance, } \\
\text { health care and a customer service } \\
\text { call centre. Gallup-Healthways } \\
\text { Wellbeing Index (WBI) }\end{array}$ \\
\hline & $\begin{array}{l}\text { Literature on presenteeism has investigated its } \\
\text { link with a large number of health risks and } \\
\text { health conditions ranging from exercise and } \\
\text { weight to allergies and irritable bowel syndrome. } \\
\text { As expected, the research on some topic areas } \\
\text { is stronger than others. Based on the research } \\
\text { reviewed, it can be said with confidence that } \\
\text { health conditions such as allergies and arthritis } \\
\text { are associated with presenteeism. Moreover, } \\
\text { health risks traditionally measured by a health } \\
\text { risk appraisal (HRA), especially physical activity } \\
\text { and body weight, also show an association with } \\
\text { presenteeism. The report recommends that } \\
\text { researchers tease out the impact of individual } \\
\text { health risks or combinations of risks and health } \\
\text { conditions on presenteeism. }\end{array}$ & $\begin{array}{l}\text { Schultz et al (2009) Searches of } \\
\text { Medline, CINAHL and PubMed in } \\
\text { October 2006, with no starting date } \\
\text { limitation with 'presenteeism' or } \\
\text { 'work limitations' as keywords. A } \\
\text { total of } 113 \text { studies were found and } \\
\text { each study was evaluated based on } \\
\text { the strength of the study design, } \\
\text { statistical analyses, outcome } \\
\text { measurement, and controlling of } \\
\text { confounding variables. }\end{array}$ \\
\hline \multirow[t]{2}{*}{$\begin{array}{l}\text { Certain } \\
\text { professions } \\
\text { Medics }\end{array}$} & $\begin{array}{l}\text { During one year, } 80 \text { per cent of the physicians } \\
\text { had worked during an illness for which they } \\
\text { would have sick-listed their patients. More than } \\
\text { half of the physicians in the study had worked } \\
\text { whilst having an infectious disease. Factors } \\
\text { independently associated with the behaviour of } \\
\text { working when ill include being in the age group } \\
30-39 \text { years, working as a clinician outside } \\
\text { hospital, having received medical treatment } \\
\text { during the last three years, and having low job } \\
\text { satisfaction. }\end{array}$ & $\begin{array}{l}\text { Rosvold and Bjertness (2001) } \\
\text { A random sample of } 1,476 \\
\text { Norwegian physicians, } 70 \text { per cent } \\
\text { answered a mailed, anonymous } \\
\text { questionnaire as a part of The } \\
\text { Norwegian Medical Association's } \\
\text { health survey. }\end{array}$ \\
\hline & $\begin{array}{l}\text { Concluded that the hospital environment } \\
\text { constitutes a fertile ground for the development } \\
\text { of workaholism among residents, particularly for } \\
\text { those who have a propensity for work addiction. }\end{array}$ & Mudrack (2006) \\
\hline $\begin{array}{l}\text { National } \\
\text { characteristics }\end{array}$ & $\begin{array}{l}\text { Cross-cultural comparison revealed that } \\
\text { presenteeism was more prevalent among } \\
\text { Chinese and they reported higher levels of } \\
\text { strains than their British counterparts. }\end{array}$ & $\begin{array}{l}\text { Using structured questionnaires, the } \\
\text { authors compared data collected } \\
\text { from samples of } 245 \text { Chinese and } \\
128 \text { British employees working in } \\
\text { various organisations and } \\
\text { industries. (Lu et al, 2013) }\end{array}$ \\
\hline
\end{tabular}




\begin{tabular}{|l|l|l|}
\hline Groups at risk & Findings & Studies \\
\hline $\begin{array}{l}\text { Some } \\
\text { industries }\end{array}$ & An Australian study highlighted industries that & KPMG/Econtech (2011) \\
& are most at risk: & A macroeconomic study of the \\
- Electricity, gas and water & impact of presenteeism on the \\
- Manufacturing. & Australian economy. \\
& $\begin{array}{l}\text { This is because of the losses in labour } \\
\text { productivity due to presenteeism and the } \\
\text { disproportionate decrease of private } \\
\text { consumption in the wider economy that } \\
\text { constitute an important demand factor for these } \\
\text { industries. (More information on this study is } \\
\text { given in Section 4.3.) }\end{array}$ & \\
& & \\
\hline
\end{tabular}




\section{Appendix 3: The impact of presenteeism on productivity}

\begin{tabular}{|c|c|c|}
\hline Factors & Findings & Research \\
\hline $\begin{array}{l}\text { General } \\
\text { poor worker } \\
\text { health }\end{array}$ & $\begin{array}{l}\text { Poor worker health and its drag on productivity } \\
\text { costs employers } \$ 576 \text { billion annually. Of that } \\
\text { amount, } 39 \text { per cent or } \$ 227 \text { billion results } \\
\text { from lost productivity tied to poor worker health } \\
\text { that drives absences and presenteeism. }\end{array}$ & $\begin{array}{l}\text { The Integrated Benefits Institute (IBI), } \\
\text { which provides research for major US } \\
\text { employers and insurers, reached its } \\
\text { estimate by drawing on } 2011 \text { US Bureau } \\
\text { of Labor Statistics wage and benefits } \\
\text { data and its own benchmarking data from } \\
60,000 \text { employers. }\end{array}$ \\
\hline Pain & $\begin{array}{l}\text { Severity of pain showed a predominantly } \\
\text { positive, linear relation to work limitations on } \\
\text { all four subscales of the WLQ. Over four } \\
\text { weeks, it was estimated that those meeting the } \\
\text { pain criterion effectively lost } 3.14 \text { days of work } \\
\text { due to presenteeism and } 0.84 \text { days due to } \\
\text { absenteeism, versus } 0.29 \text { and } 0.06 \text { days for } \\
\text { the healthy comparison group. } \\
\text { Musculoskeletal and 'mental and nervous' } \\
\text { problems topped the list. }\end{array}$ & $\begin{array}{l}\text { Allen et al (2005) } \\
\text { The impact of pain on presenteeism in a } \\
\text { Fortune } 100 \text { company using the WLQ. }\end{array}$ \\
\hline $\begin{array}{l}\text { Depression } \\
\text { Arthritis }\end{array}$ & $\begin{array}{l}\text { This study demonstrates an association } \\
\text { between employees' medical conditions and a } \\
\text { self-reported, negative impact on their } \\
\text { productivity while on the job (presenteeism). } \\
\text { Significant relationships were observed } \\
\text { between medical conditions and patterns of } \\
\text { impaired work performance. Depression was } \\
\text { highly associated with work limitations in time } \\
\text { management, interpersonal/mental } \\
\text { functioning, and overall output. Arthritis and } \\
\text { low back pain were associated with physical } \\
\text { function limitations. These two conditions were } \\
\text { also associated with limitations in } \\
\text { mental/interpersonal functioning but with low } \\
\text { back pain having the higher odds ratio. The } \\
\text { authors suggest that worksite interventions } \\
\text { (eg, disease management programmes) } \\
\text { should be tailored to the unique effects } \\
\text { observed with specific medical conditions and } \\
\text { that more targeted programmes could have } \\
\text { important benefits for productivity in the } \\
\text { workplace. }\end{array}$ & $\begin{array}{l}\text { Burton et al (2004) } \\
\text { A self-reported measure of four domains } \\
\text { of work impairment based on the Work } \\
\text { Limitations Questionnaire was completed } \\
\text { by } 16,651 \text { employees of a large US } \\
\text { financial services corporation. Uses a } \\
\text { multivariate model to control for } \\
\text { coexisting conditions, age, and gender. } \\
\text { The robust sample size in this study } \\
\text { allowed comparisons across medical } \\
\text { conditions and four different work } \\
\text { domains demonstrating that differing } \\
\text { patterns of work decrement result from } \\
\text { different medical conditions. }\end{array}$ \\
\hline
\end{tabular}




\begin{tabular}{|c|c|c|}
\hline Factors & Findings & Research \\
\hline Depression & $\begin{array}{l}\text { Workers with depression reported significantly } \\
\text { more lost productive time (LPT) than those } \\
\text { without. } 81 \text { per cent of LPT costs are } \\
\text { explained by reduced performance at work. } \\
\text { Across all respondents, mild to moderate } \\
\text { symptoms of depression were found to be } \\
\text { associated with poor work ability (measured by } \\
\text { a validated work ability questionnaire) and } \\
\text { repeated spells of certified sick leave. A } \\
\text { combination of poor work adjustments, } \\
\text { minimal line manager support and lack of early } \\
\text { tertiary psychological intervention appeared to } \\
\text { have a significant negative impact on } \\
\text { employees reporting symptoms of depression } \\
\text { and poor work ability. In-depth interviews with } \\
\text { respondents showed that those returning to } \\
\text { work following an episode of depression found } \\
\text { it more difficult to adjust back to work } \\
\text { compared with those returning to work with } \\
\text { other illnesses. The interviews also revealed a } \\
\text { pattern of negative support from line managers } \\
\text { and colleagues who had little understanding } \\
\text { about depression. }\end{array}$ & $\begin{array}{l}\text { Stewart et al (2003) } \\
692 \text { participants from the American } \\
\text { Productivity Audit } 2001 / 2 \text { screened by } \\
\text { two depression questions plus a control } \\
\text { group of } 435 \text { without depression. } \\
\text { Munir et al (2009) } \\
\text { Research funded by the Mental Health } \\
\text { Foundation examined the prevalence and } \\
\text { severity of depressive symptoms among } \\
\text { those who had returned to work in the } \\
\text { past two years following depression and } \\
\text { anxiety, back pain, heart disease or } \\
\text { cancer. Participants were recruited either } \\
\text { from the OH services of four } \\
\text { organisations (healthcare, manufacturing, } \\
\text { transport and public administration } \\
\text { sectors) or from national support groups. } \\
253 \text { responded to a questionnaire on } \\
\text { absence and post-return-to-work } \\
\text { outcomes. In addition, in-depth interviews } \\
\text { were carried out with line managers, } \\
\text { human resource (HR) managers and OH } \\
\text { professionals. }\end{array}$ \\
\hline Stress & $\begin{array}{l}\text { Workplace stress is responsible for a loss of } \\
2.14 \text { working days per employee annually as a } \\
\text { result of presenteeism, which equates to a } \\
\text { cost of } \$ 533 \text { per employee annually. }\end{array}$ & A 2008 study by Medibank Private \\
\hline $\begin{array}{l}\text { Storing up } \\
\text { future } \\
\text { problems }\end{array}$ & $\begin{array}{l}\text { Increased likelihood of future sick leave } \\
\text { Might exacerbate existing conditions and delay } \\
\text { convalescence } \\
\text { A three year follow-up of British civil servants } \\
\text { who were never sick during the period showed } \\
\text { an increased risk of serious coronary events } \\
\text { and poorer health compared to others. } 17 \text { per } \\
\text { cent of unhealthy employees took no absence } \\
\text { during the three-year follow-up. Their } \\
\text { incidence of serious coronary events was } \\
\text { twice as high as that of the unhealthy } \\
\text { employees with moderate levels of sickness } \\
\text { absenteeism. }\end{array}$ & $\begin{array}{l}\text { Longitudinal study at } 18 \text { months and } \\
\text { three years by Bergström et al (2009) } \\
\text { (Aronsson and Gustafsson, 2005) } \\
\text { Study of a representative sample }(3,136) \text {, } \\
\text { based on a supplement to Sweden's } \\
\text { regular labour market survey } 2000 \text { to } \\
2001 . \\
\text { Kivimäki et al (2005) } \\
\text { A study of } 5,071 \text { male British civil } \\
\text { servants without previous myocardial } \\
\text { infarction - baseline health screening } \\
\text { was carried out. }\end{array}$ \\
\hline Burnout & $\begin{array}{l}\text { Presenteeism gives rise to feelings of burnout } \\
\text { because of insufficient recovery. In turn, } \\
\text { burnout leads to an accumulation of the } \\
\text { workload and decreases the energy to cope, } \\
\text { causing a more accentuated presenteeism. }\end{array}$ & Demerouti et al (2009). \\
\hline
\end{tabular}




\begin{tabular}{|c|c|c|}
\hline Factors & Findings & Research \\
\hline Fatigue & $\begin{array}{l}\text { Long work hours were associated with shorter } \\
\text { sleep times, and shorter sleep times in turn } \\
\text { with more work impairments. } 37 \text { per cent of } \\
\text { respondents were classified as at-risk for any } \\
\text { sleep disorder. These individuals had more } \\
\text { negative work outcomes as compared with } \\
\text { those not at-risk for a sleep disorder. } \\
\text { Presenteeism was a significant problem for } \\
\text { individuals with insomnia symptoms, OSA and } \\
\text { RLS as compared with respondents not at- } \\
\text { risk. These results suggest that long work } \\
\text { hours may contribute to chronic sleep loss, } \\
\text { which may in turn result in work impairment. } \\
\text { Risk for sleep disorders substantially } \\
\text { increases the likelihood of negative work } \\
\text { outcomes, including occupational accidents, } \\
\text { absenteeism and presenteeism. }\end{array}$ & $\begin{array}{l}\text { Swanson et al (2011) } \\
1,000 \text { Americans who work } 30 \text { hours per } \\
\text { week or more were asked questions } \\
\text { about employment, work performance } \\
\text { and sleep in the National Sleep } \\
\text { Foundation's } 2008 \text { Sleep in America } \\
\text { telephone poll. }\end{array}$ \\
\hline Migraine & $\begin{array}{l}\text { In } 1997 \text { migraine headaches were estimated } \\
\text { to be responsible for } \$ 12 \text { billion of lost } \\
\text { productivity annually in the United States, with } \\
60 \text { to } 70 \text { per cent of this cost the result of } \\
\text { impaired performance while at work. }\end{array}$ & Schwartz et al (1997) \\
\hline $\begin{array}{l}10 \text { chronic } \\
\text { health } \\
\text { conditions }\end{array}$ & $\begin{array}{l}\text { A study of employees at the Dow Chemical } \\
\text { Company calculated the annual total costs } \\
\text { (including medical, pharmacy, absenteeism } \\
\text { and presenteeism) relating to allergies, } \\
\text { arthritis, asthma, back/neck disorder, } \\
\text { breathing disorder, depression, diabetes, heart } \\
\text { or circulatory problems, migraines and } \\
\text { stomach or bowel disorders. For each health } \\
\text { condition, the presenteeism cost was the } \\
\text { major component of cost, exceeding medical } \\
\text { care, pharmacy costs and absence costs. The } \\
\text { company estimated that lost productivity due } \\
\text { to health was equal to } 6.8 \text { per cent of the total } \\
\text { labour costs of their US workforce in } 2002 \text {. }\end{array}$ & $\begin{array}{l}\text { Collins et al (2005) The Stanford } \\
\text { Presenteeism Scale was used to assess } \\
\text { presenteeism and self-reported } \\
\text { absenteeism as part of an online health } \\
\text { survey, which was then merged with } \\
\text { healthcare cost data, pharmacy cost } \\
\text { data, job characteristics, payroll and } \\
\text { absence records. }\end{array}$ \\
\hline
\end{tabular}




\section{Potential mediators of productivity loss}

\begin{tabular}{|l|l|l|}
\hline Mediator & Results & Research \\
\hline Supervisor support & $\begin{array}{l}\text { Presenteeism had noxious effects on exhaustion for both } \\
\text { Chinese and British employees. But supervisory support } \\
\text { buffered the negative impact of presenteeism on exhaustion for } \\
\text { both Chinese and British employees. Specifically, the negative } \\
\text { relation between presenteeism and exhaustion was stronger } \\
\text { for those with more supervisory support. }\end{array}$ & $\begin{array}{l}\text { Lu et al (2013) } \\
\text { Hierarchical } \\
\text { regression } \\
\text { analyses }\end{array}$ \\
\hline Work adjustments & $\begin{array}{l}\text { The ability to adjust work to accommodate health problems } \\
\text { was significantly associated with self-reported sickness } \\
\text { performance. Those employees who were unable to adjust } \\
\text { their work around their health condition were more likely to } \\
\text { report that their performance was adversely affected when } \\
\text { working while unwell (compared with employees who were } \\
\text { able to make adjustments). } \\
\text { See Rio Tinto case (Section 4.5) }\end{array}$ & $\begin{array}{l}\text { Ashby and } \\
\text { Mahdon (2010) }\end{array}$ \\
Op. Cit. \\
\hline $\begin{array}{l}\text { Phift adjustments } \\
\text { treatments }\end{array}$ & $\begin{array}{l}\text { Hemp had suggested that relatively small investments in } \\
\text { screening, treatment and education would reap substantial } \\
\text { productivity gains. }\end{array}$ & Bemp (2004) \\
\hline $\begin{array}{l}\text { Organisational } \\
\text { support for healthy } \\
\text { lifestyles }\end{array}$ & $\begin{array}{l}\text { Employees who reported it was difficult to eat healthily at work } \\
\text { were 93 per cent more likely to have high presenteeism. Those } \\
\text { who reported that their employer had little interest in supporting } \\
\text { employee efforts to becoming more physically active were 123 } \\
\text { per cent more likely to have high presenteeism. Those who } \\
\text { indicated that their employer was not supportive in helping } \\
\text { them become emotionally healthy were 320 per cent more } \\
\text { likely to have high presenteeism. }\end{array}$ & HERO (2013) \\
\hline
\end{tabular}

